Atmos. Chem. Phys., 3, 2067-2082, 2003

www.atmos-chem-phys.org/acp/3/2067/

\title{
A revised parameterization for gaseous dry deposition in air-quality models
}

\author{
L. Zhang, J. R. Brook, and R. Vet \\ Meteorological Service of Canada, 4905 Dufferin Street, Toronto, Ontario, M3H 5T4, Canada \\ Received: 11 March 2003 - Published in Atmos. Chem. Phys. Discuss.: 28 March 2003 \\ Revised: 27 October 2003 - Accepted: 13 November 2003 - Published: 28 November 2003
}

\begin{abstract}
A parameterization scheme for calculating gaseous dry deposition velocities in air-quality models is revised based on recent study results on non-stomatal uptake of $\mathrm{O}_{3}$ and $\mathrm{SO}_{2}$ over 5 different vegetation types. Non-stomatal resistance, which includes in-canopy aerodynamic, soil and cuticle resistances, for $\mathrm{SO}_{2}$ and $\mathrm{O}_{3}$ is parameterized as a function of friction velocity, relative humidity, leaf area index, and canopy wetness. Non-stomatal resistance for other chemical species is scaled to those of $\mathrm{SO}_{2}$ and $\mathrm{O}_{3}$ based on their chemical and physical characteristics. Stomatal resistance is calculated using a two-big-leaf stomatal resistance sub-model for all gaseous species of interest. The improvements in the present model compared to its earlier version include a newly developed non-stomatal resistance formulation, a realistic treatment of cuticle and ground resistance in winter, and the handling of seasonally-dependent input parameters. Model evaluation shows that the revised parameterization can provide more realistic deposition velocities for both $\mathrm{O}_{3}$ and $\mathrm{SO}_{2}$, especially for wet canopies. Example model output shows that the parameterization provides reasonable estimates of dry deposition velocities for different gaseous species, land types and diurnal and seasonal variations. Maximum deposition velocities from model output are close to reported measurement values for different land types. The current parameterization can be easily adopted into different air-quality models that require inclusion of dry deposition processes.
\end{abstract}

\footnotetext{
Correspondence to: L. Zhang

(leiming.zhang@ec.gc.ca)
}

\section{Introduction}

Dry deposition is an important process that must be addressed in regional air-quality models. Wesely (1989) developed a parameterization scheme for estimating gaseous dry deposition velocities, which has been widely used in a number of models (RADM, Chang et al., 1987; STEM, Carmichael et al., 1991; URM, Harley et al., 1993; CMAQ, Byun and Ching, 1999). Similar dry deposition models have been developed for air-quality models around the world (e.g. Padro et al., 1991; Scire, 1991; Ganzeveld and Leieveld, 1995; Pleim and Xiu, 1995; Zhang et al., 2002a; Wu et al., 2003). Some single layer (usually called big-leaf) and multi-layer dry deposition models have also been developed for estimating acid rain and dry deposition inputs to ecosystems (e.g. Erisman et al., 1994b; Duyzer and Fowler, 1994; Meyers et al., 1998; Brook et al., 1999a; Smith et al., 2000). There are many other models involving dry deposition calculations for specific applications (e.g. Gao et al., 1993; Kramm et al., 1995; Singles et al., 1998; Mcdonald-Buller et al., 1999; Tetzlaff et al., 2002;) A review of available dry deposition models was recently reported by Wesely and Hicks (2000).

Most existing dry deposition models utilize the multiple resistance analogy approach when parameterizing the deposition velocity to vegetation and other surfaces. In this approach, the canopy resistance is usually separated into stomatal and non-stomatal portions. While the overall deposition flux is the major concern of most air-quality models, it can be important to separate the stomatal uptake of pollutants from the overall deposition for some applications (e.g. $\mathrm{O}_{3}$ dose to agricultural crops, Emberson et al., 2000; Massman et al., 2000). Separating stomatal and non-stomatal uptake leads to more accurate representation of diurnal variations of dry deposition, which is also crucial for air-quality models. Separation of these processes is necessary because stomatal uptake only occurs during the daytime for most canopy types, 
during which time it dominates over non-stomatal uptake for many chemical species.

There are many different approaches for stomatal resistance calculations ranging from simple parameterizations as functions of solar radiation and/or time of day (Wesely, 1989; Padro et al., 1991), one- or two-big-leaf approaches (Jarvis, 1976; Hicks et al., 1987; Zhang et al., 2002a), to a multilayer leaf-resistance model (Baldocchi et al., 1987). For nonstomatal resistance, a constant is typically chosen for a particular season and land type (e.g. Wesely, 1989; Zhang et al., 2002a), thereby ignoring many processes that can effect this deposition pathway. Recent measurements have demonstrated that non-stomatal uptake is affected by meteorological conditions, such as friction velocity $\left(u_{*}\right)$, relative humidity (RH) and canopy wetness, as well as biological factors, such as canopy type, leaf area index (LAI) and growing period. For example, measurements over several different canopies (forests, maize) in France (Lamaud et al., 2002; Laville et al., 2002; Lopez et al., 2002) showed that the nonstomatal uptake of $\mathrm{O}_{3}$ (i.e. the nighttime deposition) is controlled by the friction velocity. However, to date only a few models have included meteorological information in their non-stomatal formulations, e.g. $u_{*}$ in the in-canopy aerodynamic resistance and RH in the cuticle resistance (Erisman et al., 1994a, b). Recently, Zhang et al. (2002b, 2003) analyzed $\mathrm{O}_{3}$ and $\mathrm{SO}_{2}$ deposition flux data (Zhang et al., 2002b, 2003) from measurements taken over five different canopies (mixed forest, deciduous forest, corn, soybean and pasture) in the eastern USA (Meyers et al., 1998; Finkelstein et al., 2000) and proposed a new set of parameterizations for the non-stomatal resistance including in-canopy, soil and cuticle resistances. These led to better agreement between model results and measurements, thereby demonstrating the value of more detailed treatment of the processes influencing nonstomatal uptake.

The purpose of this study is to develop an improved dry deposition parameterization scheme for air quality models by including the newly developed non-stomatal resistance parameterizations (i.e., Zhang et al.; 2002b, 2003). We build upon the model (a big-leaf model) presented in Zhang et al. (2002a), which was developed for calculating dry deposition velocities for 31 gaseous species for AURAMS (Moran et al., 1998), but which only included seasonally-adjusted values for non-stomatal resistance. Other improvements to this previous model include more realistic treatment of cuticle and ground resistance in winter and the handling of seasonally-dependent input parameters.

The new model presented in this paper represents the first attempt of which we are aware to include more realistic non-stomatal uptake parameterizations for a wide range of gaseous compounds. While we show in this paper that this new model improves dry deposition estimates for $\mathrm{O}_{3}$ and $\mathrm{SO}_{2}$ and is thus expected to lead to more reliable air quality models, the new model still has many limitations and uncertainties requiring further investigation. For example, the dif- ferent non-stomatal resistance values used for $\mathrm{SO}_{2}$ over dew and rain wetted canopies are only based on results from measurements at one site (Zhang et al.; 2003). This is because sufficient $\mathrm{SO}_{2}$ flux data to estimate the required parameters are very limited. This weakness clearly points to the need for more $\mathrm{SO}_{2}$ flux data over a wide variety of conditions. Similar data for the other 29 gaseous compounds treated in this present model are scarce if not non-existent. It has therefore been necessary to resort to the approach proposed by Wesley et al. (1989), which is based upon solubility and reactivity, to include these compounds. This will continue to be a weakness of unknown uncertainty in air quality models until significant advances are made in measuring fluxes for many different compounds.

Earlier studies show that aqueous-phase chemistry plays an important role for both $\mathrm{O}_{3}$ and $\mathrm{SO}_{2}$ deposition (Fowler et al., 1979; Chamberlain, 1987; Wesely et al., 1990). Though aqueous-phase processes are considered in most air-quality models (in cloud and rain processes) this process cannot be treated explicitly in simple big-leaf dry deposition models due to the unavailability of pollutant concentrations, $\mathrm{pH}$ values and other related information at the leaf surface. Thus, uncertainties exist in simple parameterizations like the one presented here, due to variations in the aqueous-phase processes caused by variations in wetness formation mechanisms, geographical locations and many other factors. Other important processes missed in the current model include the co-deposition of $\mathrm{SO}_{2}$ and $\mathrm{NH}_{3}$ (Erisman et al., 1993, 1994b; Cape et al., 1998), bi-directional gas exchange or the compensation point (Sorteberg and Hov, 1996; Sutton et al., 1998; Flechard et al., 1999; Husted et al., 2000; Spindler et al; 2001) and the dependence of $\mathrm{SO}_{2}$ and $\mathrm{NH}_{3}$ soil resistance on soil pH (Erisman et al., 1994b). Co-deposition of $\mathrm{SO}_{2}$ and $\mathrm{NH}_{3}$ is important under wet and humid conditions and bi-directional exchange is important for emitted species. These processes are not included in the present model due to a lack of information over broad land types. Other uncertainties (as discussed in Zhang et al., 2003) include those related to the calculation of the aerodynamic and quasi-laminar resistance, which are not exact representations of the actual processes.

Obviously, errors in the flux measurements from which the model has been developed and tested also contribute to subsequent model uncertainty. Such errors are likely greater under certain conditions (e.g. nighttime stable situations) and vary by location and chemical compound. Furthermore, complete understanding of air-surface exchange processes, especially at the micro-scale, is lacking and thus model formulations and parameterizations are currently relatively simplistic representations of some, if not most, of these processes.

Despite many uncertainties discussed above, a welldeveloped big-leaf model can lead to flux estimates that are as good as some more sophisticated models (Meyers et al., 1998; Wu et al., 2003), given our present relatively limited 
knowledge about all the processes controlling dry deposition. The simpler models also have the advantage of requiring fewer assumptions regarding input parameters, which potentially avoids additional uncertainties.

The land use categories (LUC) used in Zhang et al. (2002a) are based, with some modifications, on BATS (Biosphere Atmosphere Transfer Scheme, Dickinson, 1986). This scheme was generated from 205 global land types with high resolution $(1 \mathrm{~km} \times 1 \mathrm{~km})$ satellite data. Cross-references between the original 205 land types of BATS and other schemes (e.g. SiB, Dorman and Sellers, 1989; SiB2, Sellers et al., 1996) are also available. Substantial information on LUC specified parameters (e.g. LAI, roughness length, $z_{0}$ ) are available so this scheme has been widely-used around the world. The LUC of the present work is adopted from the LUC in GEM (Coté et al., 1997), Canada's weather forecast model, and is also based on BATS, plus an extra 6 LUCs.

The next section describes in detail the model formulae. Suggested values for two important input parameters (LAI and $z_{0}$ ) are given in Sect. 3. Comparison of model results with single site measurements of $\mathrm{O}_{3}$ and $\mathrm{SO}_{2}$ dry deposition velocity and example model output are given in Sect. 4 . The nomenclature of all parameters used in this paper and definitions of 31 gaseous species are listed in an Appendix.

\section{Model description}

The scheme for the revised model is shown in Fig. 1. The primary resistances to pollutant uptake are the aerodynamic resistance $\left(R_{a}\right)$, the quasi-laminar sublayer resistance $\left(R_{b}\right)$ above the canopy, and the overall canopy resistance $\left(R_{c}\right) . R_{c}$ can be separated into two parallel paths; one is stomatal resistance $\left(R_{s t}\right)$ with its associated mesophyll resistance $\left(R_{m}\right)$, and the other is non-stomatal resistance $\left(R_{n s}\right) . R_{n s}$ can be further decomposed into resistance to soil uptake, which includes in-canopy aerodynamic resistance $\left(R_{a c}\right)$ and the subsequent soil resistance $\left(R_{g}\right)$, as well as resistance to cuticle uptake $\left(R_{\text {cut }}\right)$. Note that $R_{\text {cut }}$ here is slightly different from that defined in traditional big-leaf models in that it also considers the aerodynamic and quasi-laminar resistances of individual leaves. This is done by parameterizing $R_{c u t}$ as a function of friction velocity, similar to the concept of overall cuticle uptake considered in a multi-layer model framework (e.g. Baldocchi, 1988).

Based on the above discussion, the dry deposition velocity, $V_{d}$, is defined as:

$$
V_{d}=\frac{1}{R_{a}+R_{b}+R_{c}}
$$

where expressions for $R_{a}$ and $R_{b}$ can be found in many earlier dry deposition studies (e.g. Erisman et al., 1994b; Massman et al., 1994; Padro et al., 1991; Padro, 1996; Wesely et al., 2001). The uncertainties in $R_{a}$ and $R_{b}$ from the different models are small, although large errors can exist under

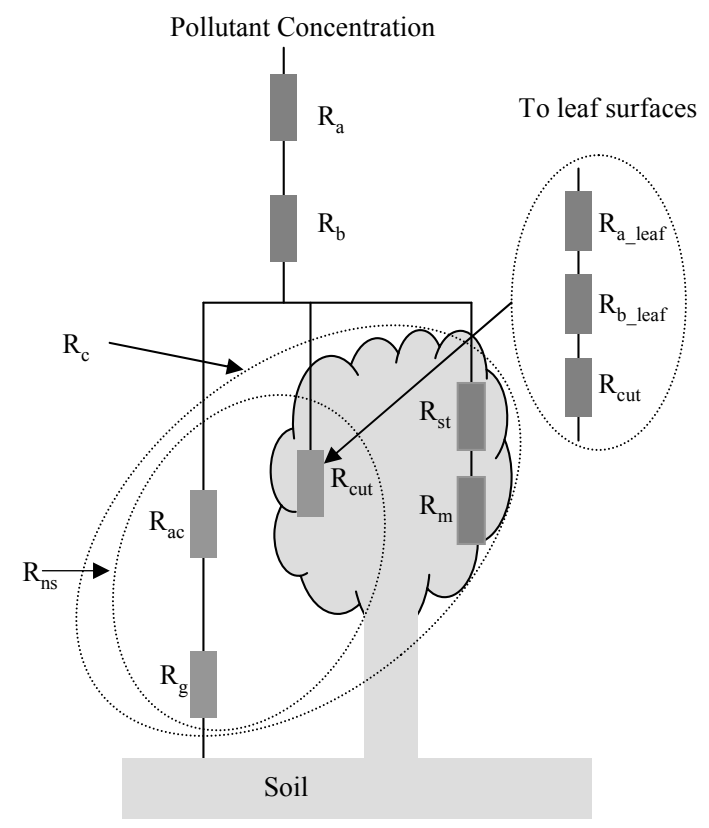

Fig. 1. Scheme of resistance analogy.

strong stable conditions (Massman et al., 1994; Zhang et al., 2003). In the present study, only $R_{c}$ is discussed. $R_{c}$ is parameterized as (Zhang et al., 2002b):

$$
\begin{aligned}
& \frac{1}{R_{c}}=\frac{1-W_{s t}}{R_{s t}+R_{m}}+\frac{1}{R_{n s}} \\
& \frac{1}{R_{n s}}=\frac{1}{R_{a c}+R_{g}}+\frac{1}{R_{c u t}}
\end{aligned}
$$

where $W_{s t}$ is the fraction of stomatal blocking under wet conditions. $R_{s t}$ is calculated using a sunlit/shade (so-called two-big-leaf) stomatal resistance sub-model (Zhang et al., 2002a). $R_{m}$ is treated as dependent only on the chemical species and we used the values for some common species considered in air-quality models as specified in Zhang et al. (2002a). Note that Eqs. (2) and (3) are for surfaces with canopies. For surfaces without canopies (e.g. water, ice, desert), $R_{s t}, R_{m}, R_{a c}$ and $R_{c u t}$ are not applicable. For the convenience of using the same equations for all LUCs, we define $R_{g}$ as the resistance to any surfaces, e.g. soil, ice, snow and water (more discussion below). Thus, for surfaces without canopies, a value of 0 is given to $R_{a c}$ and a very large value (i.e. $10^{25} \mathrm{~s} \mathrm{~m}^{-1}$ ) is used for $R_{s t}, R_{m}$ and $R_{c u t} . R_{a c}$ is not chemical species-dependent while $R_{g}$ and $R_{c u t}$ are. $R_{g}$ and $R_{\text {cut }}$ are calculated for $\mathrm{SO}_{2}$ and $\mathrm{O}_{3}$ and then scaled for other gaseous species based on the formula (similar to Wesely, 1989):

$\frac{1}{R_{x}(i)}=\frac{\alpha(i)}{R_{x}\left(\mathrm{SO}_{2}\right)}+\frac{\beta(i)}{R_{x}\left(\mathrm{O}_{3}\right)}$

where $R_{x}$ represents non-stomatal resistance components (i.e., $R_{\text {cut }}$ and $R_{g}$ ) and $i$ represents the particular gaseous 
Table 1. Land use categories and all related parameters (all resistance have a unit of $\mathrm{s} \mathrm{m}^{-1}$, na=not applicable; $\mathrm{f}(\mathrm{u})$ means a function of wind speed).

\begin{tabular}{|c|c|c|c|c|c|c|c|c|c|c|c|c|c|c|c|c|}
\hline LUC & & $R_{a c 0}$ & $\begin{array}{c}R_{\text {cut } d 0} \\
\mathrm{O}_{3}\end{array}$ & $\begin{array}{c}R_{\text {cutw0 } 0} \\
\mathrm{O}_{3}\end{array}$ & $\begin{array}{l}R_{\text {cutd } 0} \\
\mathrm{SO}_{2}\end{array}$ & $\begin{array}{l}R_{g d} \\
\mathrm{SO}_{2}\end{array}$ & $\begin{array}{c}r_{\text {stmin }} \\
\left(\mathrm{sm}^{-1}\right)\end{array}$ & $\begin{array}{c}b_{r s} \\
\left(\mathrm{Wm}^{-2}\right)\end{array}$ & $\begin{array}{l}T_{\min } \\
\left({ }^{\circ} \mathrm{C}\right)\end{array}$ & $\begin{array}{l}T_{\max } \\
\left({ }^{\circ} \mathrm{C}\right)\end{array}$ & $\begin{array}{l}T_{o p t} \\
\left({ }^{\circ} \mathrm{C}\right)\end{array}$ & $\begin{array}{c}b_{v p d} \\
\left(\mathrm{kPa}^{-1}\right)\end{array}$ & $\begin{array}{c}\psi_{c 1} \\
(\mathrm{Mpa})\end{array}$ & $\begin{array}{c}\psi_{c 2} \\
(\mathrm{Mpa})\end{array}$ & $\begin{array}{l}z_{0} \\
(\mathrm{~m})\end{array}$ & $\begin{array}{r}S d_{\max } \\
(\mathrm{cm})\end{array}$ \\
\hline 1 & water & 0 & na & na & na & 20 & na & na & na & na & na & na & na & na & $\mathrm{f}(\mathrm{u})$ & na \\
\hline 2 & ice & 0 & na & na & na & Eq. (8a) & na & na & na & na & na & na & na & na & 0.01 & 1 \\
\hline 3 & inland lake & 0 & na & na & na & 20 & na & na & na & na & na & na & na & na & $\mathrm{f}(\mathrm{u})$ & na \\
\hline 4 & evergreen needleleaf trees & 100 & 4000 & 200 & 2000 & 200 & 250 & 44 & -5 & 40 & 15 & 0.31 & -2 & -2.5 & 0.9 & 200 \\
\hline 5 & evergreen broadleaf trees & 250 & 6000 & 400 & 2500 & 100 & 150 & 40 & 0 & 45 & 30 & 0.27 & -1 & -5.0 & 2.0 & 400 \\
\hline 6 & deciduous needleleaf trees & $60-100$ & 4000 & 200 & 2000 & 200 & 250 & 44 & -5 & 40 & 15 & 0.31 & -2 & -2.5 & $0.4-0.9$ & 200 \\
\hline 7 & deciduous broadleaf trees & $100-250$ & 6000 & 400 & 2500 & 200 & 150 & 43 & 0 & 45 & 27 & 0.36 & -1.9 & -2.5 & $0.4-1.0$ & 200 \\
\hline 8 & tropical broadleaf trees & 300 & 6000 & 400 & 2500 & 100 & 150 & 40 & 0 & 45 & 30 & 0.27 & -1 & -5.0 & 2.5 & 400 \\
\hline 9 & drought deciduous trees & 100 & 8000 & 400 & 6000 & 300 & 250 & 44 & 0 & 45 & 25 & 0.31 & -1 & -4.0 & 0.6 & 200 \\
\hline 10 & evergreen broadleaf shrubs & 60 & 6000 & 400 & 2000 & 200 & 150 & 40 & 0 & 45 & 30 & 0.27 & -2 & -4.0 & 0.2 & 50 \\
\hline 11 & deciduous shrubs & $20-60$ & 5000 & 300 & 2000 & 200 & 150 & 44 & -5 & 40 & 15 & 0.27 & -2 & -4.0 & $0.05-0.2$ & 50 \\
\hline 12 & thorn shrubs & 40 & 5000 & 300 & 2000 & 200 & 250 & 44 & 0 & 45 & 25 & 0.27 & -2 & -3.5 & 0.2 & 50 \\
\hline 13 & short grass and forbs & 20 & 4000 & 200 & 1000 & 200 & 150 & 50 & 5 & 40 & 30 & 0 & -1.5 & -2.5 & 0.04 & 5 \\
\hline 14 & long grass & $10-40$ & 4000 & 200 & 1000 & 200 & 100 & 20 & 5 & 45 & 25 & 0 & -1.5 & -2.5 & $0.02-0.1$ & 20 \\
\hline 15 & crops & $10-40$ & 4000 & 200 & 1500 & 200 & 120 & 40 & 5 & 45 & 27 & 0 & -1.5 & -2.5 & $0.02-0.1$ & 10 \\
\hline 16 & rice & $10-40$ & 4000 & 200 & 1500 & 50 & 120 & 40 & 5 & 45 & 27 & 0 & -1.5 & -2.5 & $0.02-0.1$ & 10 \\
\hline 17 & sugar & $10-40$ & 4000 & 200 & 2000 & 200 & 120 & 50 & 5 & 45 & 25 & 0 & -1.5 & -2.5 & $0.02-0.1$ & 10 \\
\hline 18 & maize & $10-50$ & 5000 & 300 & 2000 & 200 & 250 & 65 & 5 & 45 & 25 & 0 & -1.5 & -2.5 & $0.02-0.1$ & 10 \\
\hline 19 & cotton & $10-40$ & 5000 & 300 & 2000 & 200 & 125 & 65 & 10 & 45 & 30 & 0 & -1.5 & -2.5 & $0.02-0.2$ & 10 \\
\hline 20 & irrigated crops & 20 & 4000 & 200 & 2000 & 50 & 150 & 40 & 5 & 45 & 25 & 0 & -1.5 & -2.5 & 0.05 & 10 \\
\hline 21 & urban & 40 & 6000 & 400 & 4000 & 300 & 200 & 42 & 0 & 45 & 22 & 0.31 & -1.5 & -3 & 1.0 & 50 \\
\hline 22 & tundra & 0 & 8000 & 400 & 2000 & 300 & 150 & 25 & -5 & 40 & 20 & 0.24 & 0 & -1.5 & 0.03 & 2 \\
\hline 23 & swamp & 20 & 5000 & 300 & 1500 & 50 & 150 & 40 & 0 & 45 & 20 & 0.27 & -1.5 & -2.5 & 0.1 & 10 \\
\hline 24 & Desert & 0 & na & na & na & 700 & na & na & na & na & na & na & na & na & 0.04 & 2 \\
\hline 25 & mixed wood forests & 100 & 4000 & 200 & 2500 & 200 & 150 & 44 & -3 & 42 & 21 & 0.34 & -2 & -2.5 & $0.6-0.9$ & 200 \\
\hline 26 & Transitional forest & 100 & 4000 & 200 & 2500 & 200 & 150 & 43 & 0 & 45 & 25 & 0.31 & -2 & -3 & $0.6-0.9$ & 200 \\
\hline
\end{tabular}

species. Parameters $\alpha$ and $\beta$ are two scaling factors based on the chemical species' solubility and half-redox reactivity (Wesely, 1989). Scaling parameters for a total of 31 species are presented in Table 1 of Zhang et al. (2002a). The details of each of the terms in Eqs. (2)-(4) are discussed below.

$W_{s t}$ : Zhang et al. (2002b), using $\mathrm{O}_{3}$ flux data from five sites in eastern North America, found that $W_{s t}$ is not important under most wet conditions because of weak solar radiation (SR), which leads to large $R_{s t}$. However, there are some exceptions to this such as morning dew and sunshine immediately after rain when solar radiation is strong. In such cases, we calculate a small $R_{s t}$ (see Eq. 6), however, stomata can be partially blocked by water films and the $W_{s t}$ term will then increase the stomatal resistance. Thus, the following formula is suggested for wet canopies (for dry canopies, $W_{s t}$ always equals 0 ):

$W_{s t}=\left\{\begin{array}{cr}0, & S R \leq 200 \mathrm{Wm}^{-2} \\ (S R-200) / 800, & 200< \\ 0.5, & S R>600 \mathrm{Wm}^{-2} \\ & S 600 \mathrm{Wm}^{-2}\end{array}\right.$

$W_{s t}$ is given a value other than 0 only when solar radiation is relatively strong $\left(>200 \mathrm{~W} \mathrm{~m}^{-2}\right.$ ) and the canopy is wet. If rain or dew occurs, the canopy is treated as wet. The occurrence of dew is defined based on particular meteorological conditions, e.g. RH, $u_{*}$ and cloud cover (Janssen and Romer, 1991) as adopted in Brook et al. (1999a). Note that Wesely (1989) increased the stomatal resistance by a factor of 3 (equivalent of a $W_{s t}$ of 0.67 ) for wet surfaces. Zhang et al. (2002a) used several constants for different wet conditions ( 0.7 for dew and 0.9 for rain). Our data show that these values are probably too large for most wet conditions and thus the new formula is suggested with an upper limit of 0.5 for $W_{s t}$.

$R_{s t}$ : The following sunlit/shade stomatal resistance submodel (Zhang et al., 2002a) is used for calculating $R_{s t}$ for all gaseous species:

$R_{s t}=1 /\left[G_{s}(P A R) f(T) f(D) f(\psi) D_{i} / D_{v}\right]$

where $G_{s}(P A R)$ is the unstressed leaf stomatal conductance, a function of photosynthetically active radiation (PAR). Calculation of $G_{s}(P A R)$ is described in Zhang et al. (2002a) and is not repeated here. The dimensionless functions $f(T)$, $f(D)$ and $f(\psi)$ represent the conductance-reducing effects of air temperature $T$, water-vapour-pressure deficit $D$, and water stress (leaf water potential) $\psi$, respectively, on leaf 
stomatal conductance (Brook et al., 1999a). The formulas for these functions are:

$f(T)=\frac{T-T_{\min }}{T_{\text {opt }}-T_{\min }}\left[\frac{T_{\max }-T}{T_{\max }-T_{\text {opt }}}\right]^{b_{t}}$

with

$b_{t}=\frac{T_{\max }-T_{o p t}}{T_{o p t}-T_{\min }}$

$f(D)=1-b_{v p d} D$

with

$D=e^{*}(T)-e$

and

$f(\psi)=\left(\psi-\psi_{c 2}\right) /\left(\psi_{c 1}-\psi_{c 2}\right)$

with

$\psi=-0.72-0.0013 S R$

$T_{\min }$ and $T_{\max }$ are minimum and maximum temperatures $\left({ }^{\circ} \mathrm{C}\right)$ that indicate the temperatures below and above which complete stomatal closure occurs. $T_{o p t}$ is an optimum temperature that indicates the temperature of maximum stomatal opening. $b_{v p d}$ is a water-vapour-pressure-deficit constant $\left(\mathrm{kPa}^{-1}\right), D$ is the vapour pressure deficit $(\mathrm{kPa}), e^{*}(T)$ is the saturation water vapour pressure $(\mathrm{kPa})$ at air temperature $T\left({ }^{\circ} \mathrm{C}\right)$, and $e$ is the ambient water vapour pressure $(\mathrm{kPa}) . \quad \psi_{c 1}$ and $\psi_{c 2}(\mathrm{MPa})$ are parameters that specify leaf-water-potential dependency. When $\psi>\psi_{c 1}$ (i.e. no leaf water potential stress), $f(\psi)=1.0$. Values for all parameters required for calculating $R_{s t}$ are taken from Brook et al. (1999a), Dorman and Sellers (1989), Dickinson et al. (1986), and NOAA (1992) library data, and are listed in Table 1. These parameters are $r_{\text {smin }}$ (minimum stomatal resistance), $b_{r s}$ (empirical light response coefficient), $T_{\min }$, $T_{\text {max }}, T_{o p t}, b_{v p d}, \psi_{c 1}$ and $\psi_{c 2}$. Explicitly consideration of the soil moisture content in $f(\psi)$ as was done in Wesely et al. (2001) is preferable, however, LUC-specific parameters for the soil moisture effect on $R_{s t}$ are very limited. Therefore an approach, which follows Sellers et al. (1996), is used as we have in the past (Brook et al., 1999a).

During nighttime when there is no solar radiation, the leaf stomata are assumed to be completely closed. $R_{s t}$ estimated from Eq. (6) then has an infinite value. Recent research suggests that the stomata of some canopy species may still be partially open even at night (Gunthardt-Goerg et al., 1997; Musselman and Minnick, 2000; Wiser and Havranek, 1993, 1995). However, this behaviour is difficult to quantify given present knowledge. In this study we treat the stomata as fully closed at night.

$R_{a c}$ : In-canopy aerodynamic resistance should be the same for all gaseous species. The formula developed in Zhang et al. (2002b) is used:

$R_{a c}=\frac{R_{a c 0} L A I^{1 / 4}}{u_{*}^{2}}$ where $R_{a c 0}$ is the reference value for in-canopy aerodynamic resistance. $R_{a c 0}$ is expected to vary with different canopy types and suggested values are given in Table 1 for all LUCs. For some LUCs, a range of $R_{a c 0}$ values is given to reflect the change of canopy structure at different times of the growing season. The minimum values, $R_{a c 0}(\min )$, correspond to leafless periods for deciduous forests and earlier growing periods for agricultural lands. The maximum values, $R_{a c 0}(\max )$, correspond to the full-leaf period for forests and the maturity period for agricultural lands. Here, a simple formula is suggested for extracting $R_{a c 0}$ values for any day of the year based on minimum and maximum $L A I$ values since this information is available in most air-quality models:

$R_{a c 0}(t)=R_{a c 0}(\min )+\frac{L A I(t)-L A I(\min )}{L A I(\max )-L A I(\min )} \times$

$\left[R_{a c 0}(\max )-R_{a c 0}(\min )\right]$

where $R_{a c 0}(t)$ corresponds to the $R_{a c 0}$ value at any day of the year. $L A I(\min )$ and $L A I(\max )$ represents minimum and maximum $L A I$ values, respectively, during the year.

Wesely (1989) specified a constant in-canopy aerodynamic resistance for forest canopies and Erisman et al. (1994b) suggested a formula as a function of canopy height and friction velocity. In the present study, canopy height is not included since its effect is implicitly included in the friction velocity and, more importantly, in the reference values of $R_{a c 0}$. As can be seen from Table 1, $R_{a c 0}$ is larger for tall canopies than for short canopies and this is consistent with Erisman et al. (1994b).

$R_{g}$ : Ground resistance is considered separately for different surface types (water, ice, snow, soil). The following equation is used according to Erisman et al. (1994b):

$R_{g}=\left\{\begin{array}{l}R_{\text {water }} \\ R_{\text {ice }} \\ R_{\text {snow }} \\ R_{\text {soil }}\end{array}\right.$

where $R_{\text {water }}, R_{\text {ice }}, R_{\text {snow }}$ and $R_{\text {soil }}$ represent resistance to water, ice, snow, and soil surfaces, respectively. $R_{\text {snow }}$ and $R_{i c e}$ are assumed to have the same values. For $\mathrm{O}_{3}, R_{\text {water }}$, $R_{\text {snow }}$ and $R_{\text {ice }}$ are given a value of $2000 \mathrm{~s} \mathrm{~m}^{-1}$. For $\mathrm{SO}_{2}$, $R_{\text {water }}$ is given a value of $20 \mathrm{~s} \mathrm{~m}^{-1}$, while $R_{\text {snow }}$ and $R_{\text {ice }}$ are taken as a function of temperature with a lower limit of $100 \mathrm{~s} \mathrm{~m}^{-1}$ and an upper limit of $500 \mathrm{~s} \mathrm{~m}^{-1}$ (Erisman et al., 1994b) as follows:

$R_{\text {snow }}, R_{\text {ice }}\left(\mathrm{SO}_{2}\right)=70(2-T)$

Information on $R_{\text {soil }}$ is limited for both $\mathrm{O}_{3}$ and $\mathrm{SO}_{2}$. Some discussion on soil resistance for $\mathrm{SO}_{2}, \mathrm{O}_{3}$ and several $\mathrm{NO}_{\mathrm{y}}$ species can be found in Erisman et al. (1994b). $\mathrm{O}_{3}$ uptake by soils is probably controlled by soil organic material (enhancing the removal) and soil moisture (inhibiting uptake by covering the reaction sites and reducing gas transfer). Based on previous studies and a review of published measurements 
(Erisman et al., 1994b; Brook et al., 1999b; Wesely and Hicks, 2000), a value of $200 \mathrm{~s} \mathrm{~m}^{-1}$ is given for $\mathrm{O}_{3}$ for all vegetated surfaces (LUC 4-19, 25 and 26) and $500 \mathrm{~s} \mathrm{~m}^{-1}$ for non-vegetated surfaces or surfaces with wet ground (LUC 20-24). $R_{\text {soil }}$ is more complicated for $\mathrm{SO}_{2}$ due to its sensitivity to wetness, dependence on soil $\mathrm{pH}$ and co-deposition with $\mathrm{NH}_{3}$ (Erisman and Wyers, 1993; Erisman et al., 1994b). Soil resistance to $\mathrm{SO}_{2}$ is usually smaller when the surface is wet, and probably different for dew- and rain-wetted surfaces, due to the different aqueous-phase chemistry involved with dew and rain (Zhang et al., 2003). The following approach is suggested for $R_{\text {soil }}$ for $\mathrm{SO}_{2}$ :

$R_{g}=\left\{\begin{array}{l}R_{\text {gd }} \\ R_{\text {grain }} \\ R_{\text {gdew }}\end{array}\right.$

where $R_{g d}$ represents the soil resistance over land surfaces where no dew or rain has occurred, $R_{\text {grain }}$ and $R_{\text {gdew }}$ are the resistances to soil when rain or dew has occured. Values of 50 and $100 \mathrm{~s} \mathrm{~m}^{-1}$ are assigned to $R_{\text {grain }}$ and $R_{\text {gdew }}$, respectively. Suggested $R_{g d}$ values for all LUCs are presented in Table 1 . For canopies with relatively high soil moisture content (e.g. tropical forest), $R_{g d}$ is given a smaller value compared to vegetation types with dry soils (e.g. desert). Note that soil $\mathrm{pH}$ and moisture content are not explicitly considered in the present study.

$R_{c u t}$ : Canopy cuticle resistance is calculated for dry and wet conditions separately according to Zhang et al. (2002b):

$$
\begin{aligned}
R_{\text {cutd }} & =\frac{R_{\text {cutd } 0}}{e^{0.03 R H} L A I^{1 / 4} u_{*}} \\
R_{\text {cutw }} & =\frac{R_{\text {cut } w 0}}{L A I^{1 / 2} u_{*}}
\end{aligned}
$$

where $R H$ is relative humidity (in percentage). $R_{\text {cutd } 0}$ and $R_{\text {cutw0 }}$ are reference values for dry and wet cuticle resistance, respectively. Values of $R_{\text {cutd } 0}$ and $R_{\text {cut } w 0}$ for $\mathrm{O}_{3}$ and values of $R_{\text {cut } d 0}$ for $\mathrm{SO}_{2}$ for each LUC are presented in Table 1. $R_{\text {cutw } 0}$ for $\mathrm{SO}_{2}$ is treated differently under dew and rain conditions. For all vegetated surfaces, values of $50 \mathrm{~s} \mathrm{~m}^{-1}$ and $100 \mathrm{~s} \mathrm{~m}^{-1}$ are given for $R_{\text {cutw } 0}$ for rain and dew conditions, respectively. Equations $(9 a)$ and $(9 b)$ were developed based on the 5-site flux data set for which $u_{*}$ values seldom exceeded $1.5 \mathrm{~m} \mathrm{~s}^{-1}$ for the two forest locations and $0.8 \mathrm{~m} \mathrm{~s}^{-1}$ for the other three sites (crops). It is expected that these equations give reasonable values for most conditions, but they may give unrealistically small values for $\mathrm{SO}_{2}$ when $u_{*}$ is extremely large (e.g. $u_{*}>2 \mathrm{~m} \mathrm{~s}^{-1}$ ). Thus, a lower limit of $100 \mathrm{~s} \mathrm{~m}^{-1}$ is suggested for dry canopies and $20 \mathrm{~s} \mathrm{~m}^{-1}$ for wet canopies for $\mathrm{SO}_{2}$. Note that Erisman et al. (1994a) first proposed modelling cuticle resistance as a function of $\mathrm{RH}$ for $\mathrm{SO}_{2}$, and similar chemical species, over dry canopies.

In winter, when temperatures are below $-1^{\circ} \mathrm{C}, R_{g d}$ and $R_{\text {cutd }}$ are increased by as much as two times (with an upper limit of 2 for the term $e^{0.2(-1-T)}$ shown below) their original value according to the formula (similar to Wesely, 1989; Erisman et al., 1994b):

$$
\begin{aligned}
& R_{g d}\left(T<-1{ }^{\circ} \mathrm{C}\right)=R_{g d} e^{0.2(-1-T)} \\
& R_{\text {cutd }}\left(T<-1{ }^{\circ} \mathrm{C}\right)=R_{\text {cutd }} e^{0.2(-1-T)}
\end{aligned}
$$

For snow on the ground and leaves, both $R_{g}$ and $R_{c u t}$ are adjusted by including a snow cover fraction $\left(f_{\text {snow }}\right)$ :

$$
\begin{gathered}
\frac{1}{R_{g}}=\frac{1-2 f_{\text {snow }}}{R_{g}}+\frac{2 f_{\text {snow }}}{R_{\text {snow }}} \\
\frac{1}{R_{\text {cut }}}=\frac{1-f_{\text {snow }}}{R_{\text {cut }}}+\frac{f_{\text {snow }}}{R_{\text {snow }}}
\end{gathered}
$$

Since snow on ground persists longer than on leaves for high canopies, the snow fraction for the ground $\left(R_{g}\right)$ is taken as 2 times that of leaves $\left(R_{\text {cut }}\right)$. Note that both $f_{\text {snow }}$ and $2 f_{\text {snow }}$ have a range of values between 0.0-1.0. Though the snow fraction might be available in some meteorological models, it represents a grid-averaged value, which probably does not represent the snow cover of canopy leaves and underlying surfaces. Considering the limited knowledge at present stage, we suggested a simple formula to estimate $f_{\text {snow }}$ from snow depth ( $\mathrm{sd}$ in $\mathrm{cm}$ ) similar to the approach used in climate models:

$f_{\text {snow }}=\frac{s d}{s d_{\max }}$

where $s d_{\max }$ is a parameter at or above which value the snow fraction for canopy leaves is assumed to be 1. Suggested $s d_{\max }$ values are also listed in Table 1 (Note that the actual $s d_{\max }$ for underlying soil surfaces is only half of the values presented in Table 1 as can be seen from the comparison of Eqs. (10c) and (10d)).

\section{Other parameters}

$L A I$ is an important parameter for calculating canopy resistances. $L A I$ values used in GEM are adopted here. Monthly $L A I$ values at the beginning of each month are presented in Fig. 2. $L A I$ values on any day are interpolated using the day number of the month. Note that several LUCs that have constant $L A I$ values are not shown in Fig. 2. They are set to 5.0 (LUC 4), 6.0 (LUC 5, 8), 4.0 (LUC 9, 23), 3.0 (LUC 10, 12), 1.0 (LUC 13) and 0.0 (LUC 1-3, 22, 24). LAI values for LUC 21 (urban) are set to a constant value of 1 in GEM. Since $L A I$ values for urban locations in different regions can have quite different seasonal variations, we chose to assign a value of 0.1 in the winter season, gradually increasing to 1 in the late spring. We keep it as 1 until early fall, and then reduce it gradually to 0.1 again at the end of fall (figure not shown). 

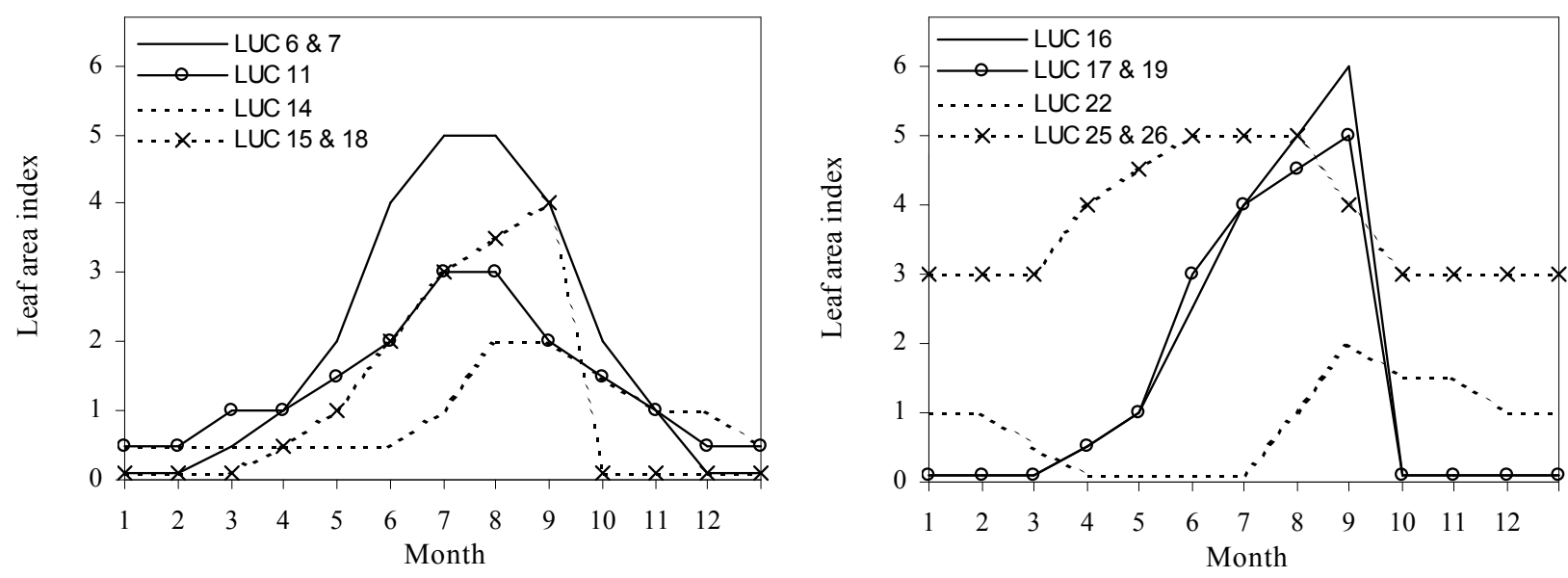

Fig. 2. Leaf area index in the Northern Hemisphere.

Roughness length $\left(z_{0}\right)$ is needed for calculating friction velocity, which subsequently affects aerodynamic, quasilaminar and non-stomatal resistances. $z_{0}$ from GEM cannot be used directly since it is treated together with topography. Dorman and Sellers (1989) presented monthly $z_{0}$ for many different land types. Panofsky and Dutton (1984) and Pielke (1984) also reviewed typical $z_{0}$ values for different land types. Based on these studies, $z_{0}$ values for each LUC are suggested and presented in Table 1. For water surfaces (LUC 1 and 3), $z_{0}$ is calculated as a function of wind speed or friction velocity (e.g. Hicks and Liss, 1976). For some surfaces a constant $z_{0}$ value is suggested, while for others a range of $z_{0}$ values is given. For those surfaces that have variable $z_{0}$ values, a formula similar to Eq. (7a) is used to obtain $z_{0}$ for any time period based on $L A I$ values:

$z_{0}(t)=z_{0}(\min )+\frac{L A I(t)-L A I(\min )}{L A I(\max )-L A I(\min )} \times$
$\left[z_{0}(\max )-z_{0}(\min )\right]$

\section{Model evaluation and example output}

\subsection{Comparison with measurements}

The major improvement of the present model is in the non-stomatal resistance parameterization, especially for wet canopies. Thus, we chose the measurements of $\mathrm{O}_{3}$ and $\mathrm{SO}_{2}$ dry deposition data at the Kane site (deciduous forest in Pennsylvania, lat: $41.595^{\circ} \mathrm{N}$, long: $78.766^{\circ} \mathrm{W}$, USA; 29 April to 23 October 1997; Finkelstein et al., 2000). This is the only site that has a sufficiently large data set for $\mathrm{O}_{3}$ and $\mathrm{SO}_{2}$ under wet canopy conditions to allow a thorough test of the performance of the revised model. Measured meteorological data $\left(u_{*}\right.$, stability, solar radiation and wetness) and biological ( $L A I)$ information are used in calculating dry deposition velocities. To show the improvements of the present model compared to its earlier version (Zhang et al., 2002a), results from both model versions for the mean diurnal cycle of half-hourly $V_{d}$ over wet canopies, along with the observations, are presented in Figs. $3 \mathrm{~b}$ and d. For dry canopies, only results from the present model are shown in Figs. 3a and $\mathrm{c}$ since the differences between the present and the previous model diurnal average results are small because the same stomatal resistance sub-model is used in both models.

The suitability of the present model can be seen from the agreement of modelled $\mathrm{O}_{3}$ and $\mathrm{SO}_{2}$ deposition velocity compared to the observations for both dry and wet canopies and the improved results compared to its previous version for wet canopies. It should be pointed out that the previous version already considered, to some extent, dew and rain effects on cuticle uptake based on the knowledge at the time the model was developed. For example, a constant cuticle resistance of $400 \mathrm{~s} \mathrm{~m}^{-1}$ and $800 \mathrm{~s} \mathrm{~m}^{-1}$ was used for $\mathrm{O}_{3}$ under rain and dew conditions, respectively, and $100 \mathrm{~s} \mathrm{~m}^{-1}$ and $200 \mathrm{~s} \mathrm{~m}^{-1}$ for $\mathrm{SO}_{2}$ under rain and dew conditions, respectively (Zhang et al., 2002a). However, this model did not agree well with observations (Figs. $3 \mathrm{c}$ and d). It overpredictes $\mathrm{O}_{3} V_{d}$ during nighttime and underestimates $\mathrm{O}_{3} V_{d}$ during the day. The new version captures the higher daily values and also maintains the lower nighttime $V_{d}$ values. The previous version seems to predict reasonable $\mathrm{SO}_{2} V_{d}$ during the night, but underestimates $\mathrm{SO}_{2} V_{d}$ during the day. It can be expected that other models, which do not adequately treat dew and rain, will exhibit even less diurnal variations than the results shown here.

Sensitivity tests show that the aerodynamic resistance alone can only explain a small portion of observed diurnal variations over wet canopies, i.e. $20-40 \%$ for $\mathrm{O}_{3}, 20-$ $50 \%$ for $\mathrm{SO}_{2}$, depending on the magnitude of the cuticle and soil resistances (non-stomatal resistance). The larger the non-stomatal resistance, the smaller the diurnal variation caused by aerodynamic resistance variation. Figure $3 b$, which shows daytime wet canopy conditions, assuming that stomatal uptake is not important for wet canopies in light of stomata blocking by water drops and the presence of very 

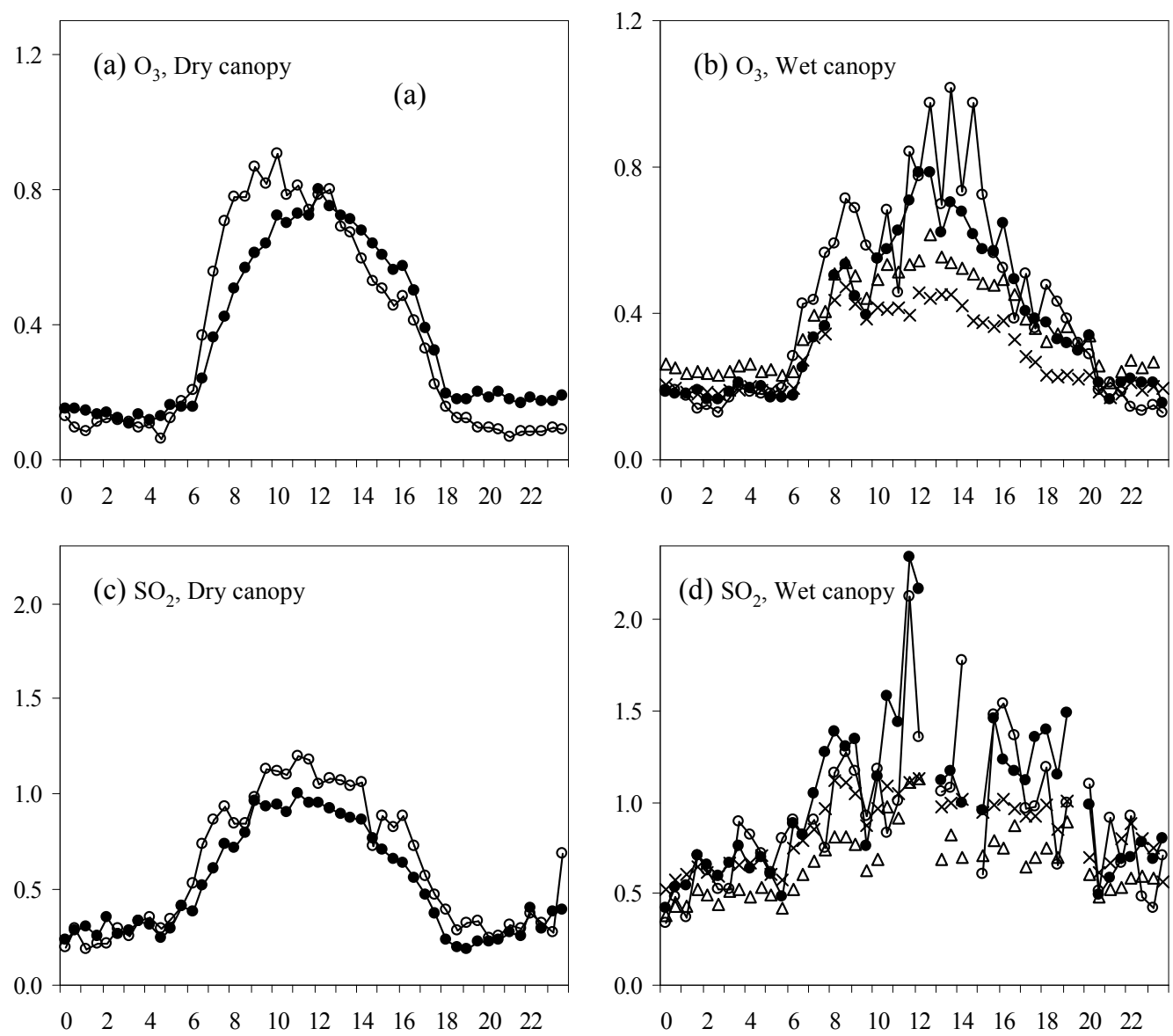

Fig. 3. Average diurnal cycle deposition velocity $\left(\mathrm{cm} \mathrm{s}^{-1}\right.$ ) from observations (open circle), current model (filled circle), previous model (triangle) and from an assumption of constant cuticle resistance for wet canopies (" $x$ " symbol).

weak solar radiation, indicates that use of a constant value of $400 \mathrm{~s} \mathrm{~m}^{-1}$ for non-stomatal resistance for $\mathrm{O}_{3}$ results in a good estimation for nighttime $\mathrm{O}_{3} V_{d}\left(\sim 0.2 \mathrm{~cm} \mathrm{~s}^{-1}\right)$. Then the model predicts a $V_{d}$ value of $0.45 \mathrm{~cm} \mathrm{~s}^{-1}$ in the early afternoon, which is much smaller than observed value at that time $\left(0.8 \sim 1.0 \mathrm{~cm} \mathrm{~s}^{-1}\right)$ (Note that the stomatal resistances are the same for all tests). This demonstrates that aerodynamic resistance alone cannot explain the observed diurnal variations. Thus earlier models fail to predict the correct diurnal cycle when cuticle uptake is not treated as a function of meteorological conditions. Similar conclusions can be drawn for $\mathrm{SO}_{2}$ except that the aerodynamic resistance can cause slightly larger diurnal variations compared to $\mathrm{O}_{3}$ because of the very small non-stomatal resistance used for $\mathrm{SO}_{2}$ over wet canopies. For example (Fig. 3d), a constant non-stomatal resistance of $80 \mathrm{~s} \mathrm{~m}^{-1}$ produces reasonable nighttime $\mathrm{SO}_{2} V_{d}\left(0.5-0.8 \mathrm{~cm} \mathrm{~s}^{-1}\right.$ compared to observations $0.4-0.8 \mathrm{~cm} \mathrm{~s}^{-1}$ ). The highest daytime $\mathrm{SO}_{2} V_{d}$ value predicted is $1.2 \mathrm{~cm} \mathrm{~s}^{-1}$ (note that the inverse of $80 \mathrm{~s} \mathrm{~m}^{-1}$ is around $1.2 \mathrm{~cm} \mathrm{~s}^{-1}$ ), which is still smaller than observed values $\left(>2 \mathrm{~cm} \mathrm{~s}^{-1}\right)$. Only when meteorological influences are explicitly included in the non-stomatal resistance (i.e. the present model), can the observed $\mathrm{SO}_{2} V_{d}$ values be reproduced.

As mentioned above, the conclusions are based on the assumption that stomatal uptake is not important for wet canopies in light of stomata blocking by water drops and the presence of very weak solar radiation, which controls stomata opening. This assumption is consistent with limited earlier studies (e.g. Fuentes et al., 1992; Grantz et al., 1995). Ultimately, this assumption is best verified using $\mathrm{CO}_{2}$ and $\mathrm{H}_{2} \mathrm{O}$ flux data over wet canopies. However, $\mathrm{CO}_{2}$ and $\mathrm{H}_{2} \mathrm{O}$ flux data at this site and the other sites we have used previously are not available. Thus further studies are still needed to verify this assumption.

\subsection{Modelled maximum $V_{d}$ values for dry and wet canopies}

Based upon the model structure described above we expect model results to be sensitive to several of the input parameters, namely $L A I, z_{0}, u_{*}, S R, T$ and $R H$. These parameters can vary widely due to meteorological variations (i.e. hourly to daily) and seasonal variations, as well as 
Table 2. Predicted maximum dry deposition velocity $\left(\mathrm{cm} \mathrm{s}^{-1}\right)$ for dry (left column) and wet (right column) canopies for 31 chemical species. A value of 0.0 (over water or ice surfaces) for some species represents a value smaller than 0.04. Definition of 31 species is listed in the appendix.

\begin{tabular}{|c|c|c|c|c|c|c|c|c|c|c|c|c|c|c|c|c|}
\hline UC & )$_{2}$ & $\mathrm{SO}_{4}$ & $\mathrm{O}_{2}$ & )$_{3}$ & $\mathrm{O}_{2}$ & $\mathrm{NO}_{3}$ & & )$_{4}$ & & iv & N & . & $\mathrm{N}$ & HO & $\mathrm{CHO}$ & $\mathrm{LD}$ \\
\hline 1 & & & & & & & & & & & & & & & & \\
\hline 2 & & & & & & & & & & & & & & & & \\
\hline 3 & & & & & & & & & & & & & & & & \\
\hline 4 & & & & & & & & & & & & & & & & \\
\hline 5 & & & & & & & & & & & & & & & & \\
\hline 6 & & & & & & & & & & & & & & & & $4,0.3$ \\
\hline 7 & & & & & & & & & & & & & & & & \\
\hline 8 & & & & & & & & & & & & & & & & $4,0.3$ \\
\hline 9 & & & & & & & & & & & & & & & & \\
\hline 10 & & & & & & & & & & & & & & & & $4,0.3$ \\
\hline 11 & & & & & & & & & & & & & & & & \\
\hline 12 & & & & & & & & & & & & & & & & 0.2 \\
\hline 13 & & & & & & & & & & & & & & & & \\
\hline 14 & & & & & & & & & & & & & & & & 0.4 \\
\hline 15 & & & & & & & & & & & & & & & & \\
\hline 16 & & & & & & & & $3.3,3.4$ & 23 & & & & & 2.6 & & $5,0.4$ \\
\hline 17 & & & & & & & & & & & & & & & & \\
\hline 18 & & & & & & & & 28 & 14 & & & & & $2,2.2$ & & $3,0.2$ \\
\hline 19 & & & & & & & & & & & & & & & & $0.4,0.3$ \\
\hline 20 & 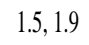 & & $0.6,0$ & $.7,0.7$ & & 3 & & 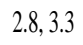 & 1 & & & & & 1.8 & 0.2 & $3,0.2$ \\
\hline 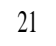 & & & & & & & & & & & & & & & & \\
\hline 22 & 0 & & & & & & & & & & & & & & & $1,0.1$ \\
\hline 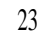 & & & & & & & & & & & & & & $9,2.5$ & & $0.4,0.3$ \\
\hline 24 & & & & & & & & & & & & & & & & $.0,0.0$ \\
\hline 25 & & & & & & & & & & & & & & $1.9,3.7$ & & $.5,0.4$ \\
\hline 26 & $.7,3.8$ & & $1.4,1.6$ & $.5,1.8$ & & & & $4.7,5.0$ & $2.1,4.2$ & & & & & $1.9,3.7$ & $0.5,0.4$ & $0.5,0.4$ \\
\hline
\end{tabular}

\begin{tabular}{|c|c|c|c|c|c|c|c|c|c|c|c|c|c|c|c|}
\hline & C4A & $\mathrm{C} 7 \mathrm{~A}$ & ACHO & MVK & MACR & MGLY & $\mathrm{MOH}$ & ETOH & $\mathrm{POH}$ & CRES & FORM & $\mathrm{ACAC}$ & $\mathrm{ROOH}$ & ONIT & INIT \\
\hline 1 & $0.0,0.0$ & $0.0,0.0$ & $0.0,0.0$ & $0.0,0.0$ & $0.0,0.0$ & $0.1,0.1$ & $1.7,1.7$ & $1.6,1.6$ & $1.3,1.3$ & $0.1,0.1$ & $2.7,2.7$ & $2.4,2.4$ & $0.5,0.5$ & $0.0,0.0$ & $0.0,0.0$ \\
\hline 2 & $0.0,0.0$ & $0.0,0.0$ & $0.0,0.0$ & $0.0,0.0$ & $0.0,0.0$ & $0.0,0.0$ & $0.5,0.5$ & $0.5,0.5$ & $0.4,0.4$ & $0.0,0.0$ & $1.4,1.4$ & $1.1,1.1$ & $0.1,0.1$ & $0.0,0.0$ & $0.0,0.0$ \\
\hline 3 & $0.0,0.0$ & $0.0,0.0$ & $0.0,0.0$ & $0.0,0.0$ & $0.0,0.0$ & $0.1,0.1$ & $1.7,1.7$ & $1.6,1.6$ & $1.3,1.3$ & $0.1,0.1$ & $2.7,2.7$ & $2.4,2.4$ & $0.5,0.5$ & $0.0,0.0$ & $0.0,0.0$ \\
\hline 4 & $0.4,0.3$ & $0.3,0.2$ & $0.3,0.3$ & $0.5,0.3$ & $0.4,0.3$ & $0.5,0.3$ & $1.4,3.0$ & $1.3,2.8$ & $1.0,2.2$ & $0.4,0.3$ & $2.4,5.2$ & $2.0,4.7$ & $1.3,1.9$ & $0.7,1.0$ & $0.7,0.9$ \\
\hline 5 & $0.4,0.3$ & $0.3,0.3$ & $0.4,0.3$ & $0.6,0.4$ & $0.4,0.3$ & $0.6,0.4$ & $1.6,3.0$ & $1.4,2.9$ & $1.1,2.2$ & $0.5,0.4$ & $2.5,5.4$ & $2.1,4.8$ & $1.3,1.7$ & $0.7,0.8$ & $0.7,0.8$ \\
\hline 6 & $0.4,0.3$ & $0.3,0.2$ & $0.3,0.3$ & $0.5,0.3$ & $0.4,0.3$ & $0.5,0.3$ & $1.4,3.0$ & $1.3,2.8$ & $1.0,2.2$ & $0.4,0.3$ & $2.4,5.2$ & $2.0,4.7$ & $1.3,1.9$ & $0.7,1.0$ & $0.7,0.9$ \\
\hline 7 & $0.4,0.3$ & $0.4,0.3$ & $0.4,0.3$ & $0.7,0.4$ & $0.4,0.3$ & $0.6,0.4$ & $1.5,2.9$ & $1.3,2.8$ & $1.1,2.1$ & $0.5,0.4$ & $2.3,5.2$ & $1.9,4.6$ & $1.2,1.5$ & $0.7,0.7$ & $0.6,0.6$ \\
\hline 8 & $0.4,0.3$ & $0.3,0.3$ & $0.4,0.3$ & $0.6,0.4$ & $0.4,0.3$ & $0.6,0.4$ & $1.6,3.0$ & $1.4,2.9$ & $1.1,2.2$ & $0.5,0.4$ & $2.5,5.4$ & $2.1,4.8$ & $1.3,1.7$ & $0.7,0.8$ & $0.7,0.8$ \\
\hline 9 & $0.3,0.2$ & $0.2,0.2$ & $0.2,0.2$ & $0.3,0.3$ & $0.3,0.2$ & $0.3,0.3$ & $0.8,2.8$ & $0.7,2.7$ & $0.6,2.1$ & $0.3,0.2$ & $1.3,5.1$ & $1.1,4.5$ & $0.8,1.4$ & $0.5,0.6$ & $0.5,0.6$ \\
\hline 10 & $0.4,0.3$ & $0.3,0.2$ & $0.3,0.2$ & $0.5,0.3$ & $0.4,0.3$ & $0.5,0.3$ & $1.2,1.9$ & $1.1,1.8$ & $0.9,1.4$ & $0.4,0.3$ & $1.8,3.2$ & $1.5,2.8$ & $1.0,1.1$ & $0.6,0.5$ & $0.5,0.5$ \\
\hline 11 & $0.4,0.3$ & $0.3,0.3$ & $0.4,0.3$ & $0.6,0.4$ & $0.4,0.3$ & $0.6,0.4$ & $1.3,1.9$ & $1.1,1.8$ & $0.9,1.5$ & $0.5,0.3$ & $1.8,3.2$ & $1.5,2.8$ & $1.1,1.2$ & $0.6,0.6$ & $0.6,0.6$ \\
\hline 12 & $0.3,0.2$ & $0.2,0.2$ & $0.3,0.2$ & $0.3,0.2$ & $0.3,0.2$ & $0.3,0.2$ & $1.0,1.9$ & $0.9,1.8$ & $0.7,1.4$ & $0.3,0.2$ & $1.7,3.2$ & $1.4,2.8$ & $0.9,1.1$ & $0.5,0.5$ & $0.5,0.5$ \\
\hline 13 & $0.2,0.2$ & $0.2,0.2$ & $0.2,0.2$ & $0.3,0.2$ & $0.2,0.2$ & $0.3,0.2$ & $1.0,1.5$ & $1.0,1.5$ & $0.7,1.1$ & $0.2,0.2$ & $1.9,2.5$ & $1.6,2.2$ & $0.8,1.0$ & $0.5,0.5$ & $0.5,0.5$ \\
\hline 14 & $0.5,0.4$ & $0.4,0.4$ & $0.4,0.4$ & $0.8,0.7$ & $0.5,0.4$ & $0.8,0.6$ & $1.6,2.0$ & $1.5,1.9$ & $1.2,1.5$ & $0.7,0.6$ & $2.2,3.0$ & $1.9,2.6$ & $1.4,1.4$ & $0.7,0.8$ & $0.7,0.7$ \\
\hline 15 & $0.5,0.4$ & $0.4,0.3$ & $0.4,0.3$ & $0.8,0.6$ & $0.5,0.4$ & $0.8,0.6$ & $1.6,2.2$ & $1.4,2.0$ & $1.2,1.6$ & $0.7,0.5$ & $2.2,3.3$ & $1.9,2.9$ & $1.4,1.5$ & $0.7,0.8$ & $0.7,0.8$ \\
\hline 16 & $0.5,0.4$ & $0.4,0.4$ & $0.5,0.4$ & $0.9,0.6$ & $0.5,0.4$ & $0.9,0.6$ & $1.8,2.3$ & $1.7,2.2$ & $1.5,1.8$ & $0.8,0.5$ & $2.4,3.5$ & $2.1,3.1$ & $1.5,1.6$ & $0.8,0.9$ & $0.7,0.8$ \\
\hline 17 & $0.5,0.4$ & $0.4,0.3$ & $0.4,0.3$ & $0.8,0.6$ & $0.5,0.4$ & $0.8,0.5$ & $1.5,2.2$ & $1.4,2.1$ & $1.2,1.7$ & $0.7,0.5$ & $2.0,3.4$ & $1.8,3.0$ & $1.4,1.5$ & $0.7,0.8$ & $0.7,0.8$ \\
\hline 18 & $0.3,0.2$ & $0.2,0.2$ & $0.3,0.2$ & $0.4,0.3$ & $0.3,0.2$ & $0.3,0.3$ & $1.0,1.9$ & $0.9,1.8$ & $0.7,1.4$ & $0.3,0.2$ & $1.7,3.2$ & $1.4,2.8$ & $0.9,1.1$ & $0.5,0.6$ & $0.5,0.5$ \\
\hline 19 & $0.4,0.3$ & $0.4,0.3$ & $0.4,0.3$ & $0.7,0.4$ & $0.4,0.3$ & $0.6,0.4$ & $1.4,2.2$ & $1.2,2.1$ & $1.0,1.7$ & $0.5,0.4$ & $2.0,3.5$ & $1.7,3.1$ & $1.2,1.3$ & $0.7,0.7$ & $0.6,0.6$ \\
\hline 20 & $0.2,0.2$ & $0.2,0.2$ & $0.2,0.2$ & $0.3,0.2$ & $0.2,0.2$ & $0.3,0.2$ & $1.3,1.6$ & $1.2,1.5$ & $0.9,1.2$ & $0.3,0.2$ & $2.0,2.6$ & $1.7,2.3$ & $0.8,0.9$ & $0.4,0.4$ & $0.4,0.4$ \\
\hline 21 & $0.2,0.1$ & $0.2,0.1$ & $0.2,0.1$ & $0.2,0.2$ & $0.2,0.1$ & $0.2,0.2$ & $0.7,2.1$ & $0.6,2.0$ & $0.5,1.5$ & $0.2,0.2$ & $1.4,4.2$ & $1.1,3.5$ & $0.6,0.9$ & $0.4,0.3$ & $0.3,0.3$ \\
\hline 22 & $0.1,0.1$ & $0.1,0.1$ & $0.1,0.1$ & $0.1,0.1$ & $0.1,0.1$ & $0.1,0.2$ & $0.7,1.8$ & $0.6,1.7$ & $0.4,1.3$ & $0.1,0.1$ & $1.4,3.1$ & $1.1,2.7$ & $0.5,0.8$ & $0.3,0.3$ & $0.2,0.3$ \\
\hline 23 & $0.4,0.3$ & $0.3,0.3$ & $0.4,0.3$ & $0.6,0.4$ & $0.4,0.3$ & $0.6,0.4$ & $1.7,2.1$ & $1.6,2.0$ & $1.3,1.6$ & $0.6,0.4$ & $2.4,3.3$ & $2.1,3.0$ & $1.2,1.2$ & $0.6,0.6$ & $0.5,0.5$ \\
\hline 24 & $0.0,0.0$ & $0.0,0.0$ & $0.0,0.0$ & $0.0,0.0$ & $0.0,0.0$ & $0.0,0.0$ & $0.1,1.0$ & $0.1,1.0$ & $0.1,0.7$ & $0.0,0.0$ & $0.3,2.2$ & $0.2,1.9$ & $0.2,0.3$ & $0.1,0.1$ & $0.1,0.1$ \\
\hline 25 & $0.4,0.3$ & $0.4,0.3$ & $0.4,0.3$ & $0.7,0.5$ & $0.4,0.3$ & $0.7,0.4$ & $1.6,3.1$ & $1.4,2.9$ & $1.2,2.2$ & $0.6,0.4$ & $2.5,5.2$ & $2.1,4.7$ & $1.5,2.0$ & $0.8,1.0$ & $0.8,1.0$ \\
\hline 26 & $0.4,0.3$ & $0.4,0.3$ & $0.4,0.3$ & $0.7,0.5$ & $0.4,0.3$ & $0.7,0.4$ & $1.6,3.1$ & $1.4,2.9$ & $1.1,2.2$ & $0.6,0.4$ & $2.5,5.2$ & $2.0,4.7$ & $1.5,2.0$ & $0.8,1.0$ & $0.8,1.0$ \\
\hline
\end{tabular}


geographic variations. Due to these large variations, it is difficult to provide typical $V_{d}$ values from the model. We therefore ran the model for a wide, but realistic range of input values for these parameters, and estimated the typical range of $V_{d}$ values and compared them with published measurements. Here we present the results for each LUC under dry and wet canopy conditions assuming a reference height for the $V_{d}$ calculation of $20 \mathrm{~m}$. The range of $u_{*}$ values used depended upon the LUCs with the two roughest surfaces, evergreen and tropical broadleaf forests (LUC 5 and 8), being assigned values within the range of $0.1-1.5 \mathrm{~m} \mathrm{~s}^{-1}$; forests and urban areas, a range of $0.1-1.2 \mathrm{~m} \mathrm{~s}^{-1}$; and the remaining surfaces, a range of $0.1-0.8 \mathrm{~m} \mathrm{~s}^{-1}$. These values were taken from available observation data (Meyers et al., 1998; Finkelstein et al., 2000). Surface temperature was allowed to vary between -10 and $30^{\circ} \mathrm{C}$, solar radiation from 0 to $800 \mathrm{~W} \mathrm{~m}^{-2}$ and relative humidity from $50-90 \%$. All possible contributions of $u_{*}, T, S R$ and $R H$ were input separately into the model (using small increments for all variables: 0.1 for $u_{*}, 1^{\circ} \mathrm{C}$ for $T, 50 \mathrm{~W} \mathrm{~m}^{-2}$ for $S R$ and $5 \%$ for $R H$ ) to calculate the range of $V_{d}$ values possible for each LUC. In addition, calculations were done for the first day of every month so that the seasonal variation of $L A I$ was accounted for. Since, realistically, some of the test conditions would be highly unlikely (e.g. high temperatures and large solar radiation over tundra), the allowed ranges were adjusted so that $5^{\circ} \mathrm{C}$ is the minimum temperature for tropical forests and $20^{\circ} \mathrm{C}$ and $500 \mathrm{~W} \mathrm{~m}^{-2}$ are the maximum values for tundra. We expect that the maximum $V_{d}$ values (Table 2) extracted from these model test runs will be representative of the realworld typical maximum $V_{d}$, excluding some extreme conditions (e.g. $\sim 1 \%$ largest values ever observed), for most land types under dry and wet conditions.

The maximum calculated $V_{d}$ values for dry forest canopies and agricultural lands range around $0.9-1.7 \mathrm{~cm} \mathrm{~s}^{-1}$ for $\mathrm{SO}_{2}$, $0.6-1.5 \mathrm{~cm} \mathrm{~s}^{-1}$ for $\mathrm{O}_{3}$ and $3.3-5.3 \mathrm{~cm} \mathrm{~s}^{-1}$ for $\mathrm{HNO}_{3}$. NO2 $V_{d}$ follows the pattern of $\mathrm{O}_{3} V_{d}$ but with slightly smaller values $(\alpha=0, \beta=0.8) . \mathrm{H}_{2} \mathrm{O}_{2} \quad V_{d}$ is higher than both $\mathrm{SO}_{2}$ and $\mathrm{O}_{3}$ during both day and night $(\alpha=1, \beta=1) . \mathrm{HNO}_{3}$ has the highest $V_{d}$ among all the chemical species considered here due to its high solubility and reactivity $(\alpha=10, \beta=10)$. The $V_{d}$ of PAN mimics the pattern of $\mathrm{O}_{3}(\alpha=0, \beta=0.6)$ but is always smaller while the $V_{d}$ of HCHO follows the pattern of $\mathrm{SO}_{2}(\alpha=0.8, \beta=0.2) . \mathrm{NH}_{3}$ is similar to $\mathrm{SO}_{2}(\alpha=1, \beta=0)$, but slightly higher during the day due to its higher molecular diffusivity (Note that bi-directional exchange for $\mathrm{NH}_{3}$ is not treated in the present study). The $V_{d}$ of ROOH is similar to the values for $\mathrm{O}_{3}(\alpha=0.1, \beta=0.8)$. The $V_{d}$ of $\mathrm{H}_{2} \mathrm{SO}_{4}$ and $\mathrm{HNO}_{2}$ follows the pattern of $\mathrm{HNO}_{3}$ but is smaller. Minimum $V_{d}$ values (not presented in Table 2) for most chemical species are around $0.01-0.05 \mathrm{~cm} \mathrm{~s}^{-1}$ for most LUCs. It could be even smaller if $u_{*}$ were given smaller values (e.g. $<0.1 \mathrm{~s} \mathrm{~m}^{-1}$ ).

Maximum $\mathrm{SO}_{2}$ (and other similar species) $V_{d}$ values for wet canopies are much larger than for dry canopies due to
$\mathrm{SO}_{2}$ solubility and reactivity. The increases are usually larger for canopies with larger $L A I$. Maximum $\mathrm{O}_{3}$ (and other similar species) $V_{d}$ values for wet canopies are very close to those for dry canopies, due to the two contradictory factors, the increase in cuticle uptake and the decrease in stomatal blocking (Zhang et al., 2002b).

As mentioned above, values in Table 2 do not cover the extreme conditions. If $u_{*}$ is larger than values used above, $V_{d}$ values can be larger than those presented in Table 2. For example, if a value of $1.5 \mathrm{~m} \mathrm{~s}^{-1}$ instead of $1.2 \mathrm{~m} \mathrm{~s}^{-1}$ was used for $u_{*}$ over deciduous forests (LUC 6 and 7), maximum $\mathrm{O}_{3} V_{d}$ values would be $2.0 \mathrm{~cm} \mathrm{~s}^{-1}$ and $1.4 \mathrm{~cm} \mathrm{~s}^{-1}$ for LUC 6 and 7, respectively. The larger $u_{*}$ values are possible considering the large roughness length of forests. For example, of 2722 available $u_{*}$ measurement samples at Kane site (deciduous forest) discussed in Sect. 4.1, 31 ( $\sim 1 \%$ of total samples) have values larger than $1.2 \mathrm{~m} \mathrm{~s}^{-1}$ and 6 have values larger than $1.5 \mathrm{~m} \mathrm{~s}^{-1}$. Measured $\mathrm{O}_{3} V_{d}$ for the same site has $5 \%$ larger than $1.2 \mathrm{~cm} \mathrm{~s}^{-1}$ and $1 \%$ larger than $1.5 \mathrm{~cm} \mathrm{~s}^{-1}$. It seems that the model can predict large enough $\mathrm{O}_{3} V_{d}$ for needleleaf forests, even for extreme conditions compared to measurements $\left(\sim 2 \mathrm{~cm} \mathrm{~s}^{-1}\right)$. The model fails to predict extreme $\mathrm{O}_{3} \quad V_{d}$ for broadleaf forests (including tropical forest), unless even larger $u_{*}$ values are used. This is caused by too large values chosen for two input parameters $\left(R_{\text {cut } d 0}\right.$ and $R_{\text {cut } w 0}$ ), which seems to work well if extreme conditions $(\sim 1 \%)$ are excluded. As discussed in Zhang et al. (2002), the model was developed using measurements that exclude (1 to $3 \%)$ extreme conditions.

Zhang et al. (2002a) reviewed and discussed all published measurements for all species of interest. Most flux measurements of $\mathrm{SO}_{2}, \mathrm{O}_{3}, \mathrm{NO} 2, \mathrm{NH}_{3}$ and $\mathrm{HNO}_{3}$ support the results generated from the present model. The very limited set of measurements for PAN, $\mathrm{HCHO}, \mathrm{H}_{2} \mathrm{O}_{2}$ and $\mathrm{ROOH}$ also agree well with model results. As indicated earlier, there are no data for the other species and thus Table 2 provides only a first-order estimation of their deposition rates, which cannot be validated at present stage.

\subsection{Modelled typical $V_{d}$ values under different dry and wet conditions}

To attempt to provide an indication of the typical $V_{d}$ values (instead of the maximum range as shown in Table 2) and to demonstrate the effect of day vs. night, wet vs. dry and snow conditions, we ran the model again using typical values for the input parameters. Table 3 lists the $u_{*}$ values used for different LUCs for several typical conditions. Note that $u_{*}$ for dry and rainy summer days was given the same set of values, as for dry and rainy summer night, while $u_{*}$ for dewy summer nights was assumed smaller values. Typically LUC 5 (evergreen broadleaf trees) and 8 (tropical broadleaf trees) can expect to have the largest $u_{*}$ values reflecting their large roughness; conversely, smooth surfaces (ice, water, tundra) have the smallest $u_{*}$ values. The other dominant 
Table 3. Friction velocity $\left(\mathrm{m} \mathrm{s}^{-1}\right)$ used for producing Table 4 .

\begin{tabular}{|c|c|c|c|c|c|}
\hline LUC & & $\begin{array}{c}\text { Day } \\
\text { dry or rain }\end{array}$ & $\begin{array}{c}\text { Night } \\
\text { dry or rain }\end{array}$ & $\begin{array}{l}\text { Night } \\
\text { dew }\end{array}$ & $\begin{array}{l}\text { Day } \\
\text { Snow }\end{array}$ \\
\hline 1 & water & 0.3 & 0.25 & 0.2 & 0.3 \\
\hline 2 & ice & 0.25 & 0.15 & 0.15 & 0.25 \\
\hline 3 & inland lake & 0.25 & 0.2 & 0.2 & 0.25 \\
\hline 4 & evergreen needleleaf trees & 0.6 & 0.3 & 0.2 & 0.45 \\
\hline 5 & evergreen broadleaf trees & 0.7 & 0.35 & 0.2 & 0.5 \\
\hline 6 & deciduous needleleaf trees & 0.6 & 0.3 & 0.2 & 0.45 \\
\hline 7 & deciduous broadleaf trees & 0.6 & 0.3 & 0.2 & 0.45 \\
\hline 8 & tropical broadleaf trees & 0.7 & 0.35 & 0.2 & 0.5 \\
\hline 9 & drought deciduous trees & 0.6 & 0.3 & 0.2 & 0.45 \\
\hline 10 & evergreen broadleaf shrubs & 0.4 & 0.2 & 0.2 & 0.3 \\
\hline 11 & deciduous shrubs & 0.4 & 0.2 & 0.2 & 0.3 \\
\hline 12 & thorn shrubs & 0.4 & 0.2 & 0.2 & 0.3 \\
\hline 13 & short grass and forbs & 0.4 & 0.2 & 0.2 & 0.3 \\
\hline 14 & long grass & 0.4 & 0.2 & 0.2 & 0.3 \\
\hline 15 & crops & 0.4 & 0.2 & 0.2 & 0.3 \\
\hline 16 & rice & 0.4 & 0.2 & 0.2 & 0.3 \\
\hline 17 & sugar & 0.4 & 0.2 & 0.2 & 0.3 \\
\hline 18 & maize & 0.4 & 0.2 & 0.2 & 0.3 \\
\hline 19 & cotton & 0.4 & 0.2 & 0.2 & 0.3 \\
\hline 20 & irrigated crops & 0.4 & 0.2 & 0.2 & 0.3 \\
\hline 21 & urban & 0.6 & 0.3 & 0.2 & 0.45 \\
\hline 22 & tundra & 0.25 & 0.15 & 0.15 & 0.25 \\
\hline 23 & swamp & 0.4 & 0.2 & 0.2 & 0.3 \\
\hline 24 & Desert & 0.25 & 0.15 & 0.15 & 0.25 \\
\hline 25 & mixed wood forests & 0.6 & 0.3 & 0.2 & 0.45 \\
\hline 26 & Transitional forest & 0.6 & 0.3 & 0.2 & 0.45 \\
\hline
\end{tabular}

meteorological variables used for the tests are: $20^{\circ} \mathrm{C}(T)$, $75 \%(R H)$ and $600 \mathrm{Wm}^{-2}(S R)$ for dry summer day; $20^{\circ} \mathrm{C}$ $(T)$ and $200 \mathrm{Wm}^{-2}(S R)$ for rain summer day; $10^{\circ} \mathrm{C}(T)$ and $75 \%(R H)$ for dry summer night; and $-2^{\circ} \mathrm{C}(T)$ and $20 \mathrm{~cm}$ $(S D)$ for snow-covered conditions (note that for ice surfaces, the temperature is given a value of $-2^{\circ} \mathrm{C}$ for all the tests). Only 5 chemical species are presented here (Table 4) as examples. Results for other species can be obtained by comparing their two scaling parameters ( $\alpha$ and $\beta$ in Zhang et al., $2002 \mathrm{a}$ ) and by comparing their maximum $V_{d}$ values in Table 2 with those of the 5 species shown.

For $\mathrm{SO}_{2}$ and $\mathrm{O}_{3}, V_{d}$ is found to typically be around $0.6-$ $0.9 \mathrm{~cm} \mathrm{~s}^{-1}$ for a summer day for most vegetated surfaces with dry canopy conditions. As expected, $V_{d}$ is larger over canopies with larger $L A I$ (e.g. forests) and smaller $r_{s m i n}$ (e.g. crops LUCs 15-17). Stomatal resistance is the dominant term during dry daytime conditions. When canopies are wet due to rain, $\mathrm{SO}_{2} V_{d}$ increases substantially for vegetated surfaces due to increased cuticle uptake. During nighttime over dry canopies, $\mathrm{SO}_{2} V_{d}$ is around $0.2-0.4 \mathrm{~cm} \mathrm{~s}^{-1}$, and $\mathrm{O}_{3}$ $V_{d}$ is $0.1-0.3 \mathrm{~cm} \mathrm{~s}^{-1}$. $V_{d}$ of $\mathrm{SO}_{2}$ is larger than that of $\mathrm{O}_{3}$ due to the smaller cuticle and soil resistances assigned to $\mathrm{SO}_{2}$. During nighttime over wet canopies caused by rain,
$V_{d}$ of $\mathrm{O}_{3}$ is slightly larger compared to dry nighttime conditions, while $V_{d}$ of $\mathrm{SO}_{2}$ is substantially larger. The main result is that when canopies are wetted by dew, both $\mathrm{SO}_{2}$ and $\mathrm{O}_{3}$ have slightly larger $V_{d}$ values compared to dry nighttime conditions assuming $u_{*}$ values are the same. However, since $u_{*}$ under dew conditions is usually smaller than under dry and rainy conditions (as was found in Zhang et al., 2003), $V_{d}$ values under dew conditions are not necessarily larger than under dry conditions, as shown in Table 4. In winter when there is snow, $\mathrm{SO}_{2} V_{d}$ is around $0.4 \mathrm{~cm} \mathrm{~s}^{-1}$. However, it can be close to $1 \mathrm{~cm} \mathrm{~s}^{-1}$ over snow surfaces if the temperature is higher than $1^{\circ} \mathrm{C}$ (see Eq. 8a). $\mathrm{O}_{3} V_{d}$ is less than $0.1 \mathrm{~cm} \mathrm{~s}^{-1}$ if the surfaces are fully covered by snow, but can be higher than 0.2 if the surfaces are partially covered by snow (e.g. forest canopies). It is well known that surface resistance $\left(R_{c}\right)$ for $\mathrm{HNO}_{3}$ is very small (i.e. $\left.<20 \mathrm{~s} \mathrm{~m}^{-1}\right)$. Thus, aerodynamic resistance $\left(R_{a}\right)$ usually dominates the rate of $\mathrm{HNO}_{3}$ dry deposition. However, $R_{c}$ of $\mathrm{HNO}_{3}$ can be substantially larger (e.g. $>100 \mathrm{~s} \mathrm{~m}^{-1}$ ) under very dry conditions (e.g. $R H<20 \%$, Tarnay et al., 2002). Many models specify a lower limit for $R_{c}$ of $\mathrm{HNO}_{3}$ (e.g. $10 \mathrm{~s} \mathrm{~m}^{-1}$ in Wesely, 1989 and Brook et al., 1999a). In the present study, we do not set a lower limit, but calculate $R_{c}$ for $\mathrm{HNO}_{3}$ using two 
Table 4. Predicted dry deposition velocity $\left(\mathrm{cm} \mathrm{s}^{-1}\right)$ for chemical species $\mathrm{SO}_{2}, \mathrm{HCHO}, \mathrm{O}_{3}, \mathrm{PAN}$ and $\mathrm{HNO}_{3}$ under 6 typical conditions: dry summer day, rain summer day, dry summer night, dew summer night, rain summer night and winter day with snow.

\begin{tabular}{|c|c|c|c|c|c|c|c|c|c|c|c|c|c|c|c|c|c|c|c|c|c|c|c|c|c|c|c|c|c|c|}
\hline \multirow[t]{2}{*}{ LUC } & \multicolumn{6}{|c|}{$\mathrm{SO}_{2}$} & \multicolumn{6}{|c|}{$\mathrm{HCHO}$} & \multicolumn{6}{|c|}{$\mathrm{O}_{3}$} & \multicolumn{6}{|c|}{ PAN } & \multicolumn{6}{|c|}{$\mathrm{HNO}_{3}$} \\
\hline & $\begin{array}{l}\text { Dry } \\
\text { Day }\end{array}$ & $\begin{array}{l}\text { Rain } \\
\text { Day }\end{array}$ & $\begin{array}{l}\text { Dry } \\
\text { Night }\end{array}$ & $\begin{array}{l}\text { Dew } \\
\text { Night }\end{array}$ & Night & Day & $\begin{array}{l}\text { Dry } \\
\text { Day }\end{array}$ & Day & $\begin{array}{c}\text { Dry } \\
\text { Night }\end{array}$ & Night & Night & Day & Day & $\begin{array}{l}\text { Rain } \\
\text { Day }\end{array}$ & Night & & Night & $\begin{array}{l}\text { Snow } \\
\text { Day }\end{array}$ & Day & $\begin{array}{l}\text { Rain } \\
\text { Day }\end{array}$ & $\begin{array}{l}\text { Dry } \\
\text { Night }\end{array}$ & $\begin{array}{l}\text { Dew } \\
\text { Night }\end{array}$ & $\begin{array}{l}\text { Rain } \\
\text { Night }\end{array}$ & $\begin{array}{l}\text { Snow } \\
\text { Day }\end{array}$ & $\begin{array}{l}\text { Dry } \\
\text { Day }\end{array}$ & $\begin{array}{l}\text { Rain } \\
\text { Day }\end{array}$ & $\begin{array}{l}\text { Dry } \\
\text { Night }\end{array}$ & $\begin{array}{l}\text { Dew } \\
\text { Night }\end{array}$ & $\begin{array}{l}\text { Rain } \\
\text { Night }\end{array}$ & $\begin{array}{c}\text { Snow } \\
\text { Day }\end{array}$ \\
\hline 1 & 0.92 & 0.92 & 0.71 & 0.53 & 0.71 & 0.89 & 0.91 & 0.91 & 0.71 & 0.54 & 0.71 & 0.88 & 0.05 & 0.05 & 0.05 & 0.05 & 0.05 & 0.05 & 0.03 & 0.03 & 0.03 & 0.03 & 0.03 & 0.03 & 1.01 & 1.01 & 0.76 & 0.56 & 0.76 & 0.97 \\
\hline 2 & 0.55 & 0.55 & 0.39 & 0.36 & 0.39 & 0.55 & 0.5 & 0.5 & 0.37 & 35 & 0.37 & 0.5 & 0.05 & 0.05 & 0.05 & 0.05 & 0.05 & 0.05 & 0.03 & 0.03 & 0.03 & 0.03 & 0.03 & 0.03 & 1.1 & 1.1 & 0.61 & 0.54 & 0.61 & 1.08 \\
\hline 3 & 0.79 & 0.79 & 0.58 & 0.53 & 0.58 & 0.76 & 0.79 & 0.79 & 0.59 & 0.54 & 0.59 & 0.76 & 0.05 & 0.05 & 0.05 & 0.05 & 0.05 & 0.05 & 0.03 & 0.03 & 0.03 & 0.03 & 0.03 & 0.03 & 0.86 & 0.86 & 0.62 & 0.56 & 0.62 & 0.82 \\
\hline 4 & 0.84 & 1.94 & 0.24 & 0.35 & 0.87 & 0.36 & 0.95 & 1.88 & 0.22 & 0.34 & 0.82 & 0.35 & 0.73 & 0.91 & 0.15 & 0.21 & 0.34 & 0.23 & 0.51 & 0.62 & 0.11 & 0.1 & 0.23 & 0.17 & 2.97 & 3.39 & 1.35 & 1.17 & 1.88 & 1.96 \\
\hline 5 & 0.88 & 2.47 & 0.22 & 0.38 & 1.12 & 0.29 & 1.01 & 2.36 & 0.2 & 0.35 & 1.03 & 0.26 & 74 & 0.79 & 0.11 & 0.12 & 0.23 & 0.15 & 0.51 & 0.53 & 0.08 & 0.08 & 0.15 & 0.11 & 3.34 & 4.07 & 1.53 & 1.31 & 2.39 & 2.03 \\
\hline 6 & 0.84 & 1.94 & 0.24 & 0.35 & 0.87 & 0.33 & 0.94 & 1.88 & 0.22 & 0.33 & 0.81 & 0.32 & 0.73 & 0.91 & 0.15 & 0.21 & 0.33 & 0.25 & 0.51 & 0.62 & 0.11 & 0.14 & 0.22 & 0.17 & 2.96 & 3.39 & 1.35 & 1.17 & 1.88 & 1.35 \\
\hline 7 & 0.8 & 1.92 & 0.18 & 0.35 & 0.86 & 0.2 & 0.93 & 1.84 & 0.16 & 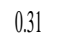 & 0.79 & 026 & 71 & 0.66 & 0.09 & 0.11 & 0.18 & 0.2 & 0.49 & 0.45 & 0.06 & 0.07 & 0.12 & 0.14 & 2.66 & 3.42 & 1.2 & 1.14 & 1.91 & 1.15 \\
\hline 8 & 0.87 & 2.5 & 0.22 & 0.39 & 1.14 & 0.28 & 1 & 2.38 & 0.2 & 0.35 & 1.04 & 0.26 & 0.73 & 0.78 & 0.11 & 0.12 & 0.22 & 0.14 & 0.51 & 0.52 & 0.07 & 0.08 & 0.15 & 0.1 & 3.41 & 4.18 & 1.56 & 1.36 & 2.48 & 2.06 \\
\hline 9 & 0.48 & 1.77 & 0.11 & 0.32 & 0.8 & 0.19 & 0.57 & 1.68 & 0.11 & 0.29 & 0.73 & 0.19 & 0.51 & 0.59 & 0.1 & 0.12 & 0.19 & 0.15 & 0.36 & 0.41 & 0.08 & 0.08 & 0.13 & 0.12 & 1.79 & 3.25 & 0.79 & 1.04 & 1.78 & 1.21 \\
\hline 10 & 0.63 & 1.1 & 0.3 & 0.29 & 0.46 & 0.28 & 0.73 & 1.08 & 0.27 & 0.27 & 0.42 & 0.25 & 0.57 & 0.5 & 0.12 & 0.12 & 0.12 & 0.1 & 0.41 & 0.36 & 0.09 & 0.09 & 0.09 & 0.07 & 1.62 & 2.15 & 0.96 & 0.88 & 1.06 & 1.2 \\
\hline 11 & 0.71 & 1.12 & 0.3 & 0.29 & 0.46 & 0.35 & 0.84 & 1.12 & 0.27 & 0.27 & 0.42 & 0.32 & 0.68 & 0.6 & 0.14 & 0.14 & 0.14 & 0.15 & 0.49 & 0.43 & 0.1 & 0.1 & 0.1 & 0.09 & 1.67 & 2.15 & 0.97 & 0.89 & 1.06 & 1.08 \\
\hline 12 & 0.57 & 1.09 & 0.31 & 0.3 & 0.47 & 0.3 & 0.63 & 1.06 & 0.29 & 0.28 & 0.44 & 0.27 & 0.5 & 0.5 & 0.16 & 0.16 & 0.16 & 0.12 & 0.36 & 0.35 & 0.12 & 0.12 & 0.12 & 0.08 & 1.64 & 2.15 & 0.97 & 0.89 & 1.07 & 1.22 \\
\hline 13 & 0.64 & 0.9 & 0.27 & 0.26 & 0.37 & 0.42 & 0.66 & 0.89 & 0.26 & 075 & 0.35 & 0.38 & 0.5 & 0.51 & 0.2 & 0.19 & 0.2 & 0.09 & 0.36 & 0.36 & 0.15 & 0.1 & 0.15 & 0.06 & 1.62 & 1.85 & 0.76 & 0.7 & 0.84 & 1.22 \\
\hline 14 & 0.74 & 0.97 & 0.27 & 0.26 & 0.37 & 0.45 & 0.81 & 0.99 & 0.26 & 0.25 & 0.35 & 0.4 & 0.63 & 0.63 & 0.2 & 0.19 & 0.2 & 0.09 & 0.46 & 0.45 & 0.15 & 0.15 & 0.15 & 0.06 & 1.65 & 1.87 & 0.77 & 0.7 & 0.85 & 1.18 \\
\hline 15 & 0.8 & 1.12 & 0.31 & 0.3 & 0.45 & 0.46 & 0.91 & 1.14 & 0.3 & 0.29 & 0.43 & 0.41 & 0.75 & 0.71 & 0.21 & 0.2 & 0.21 & 0.0 & 0.55 & 0.51 & 0.15 & 0.1 & 0.15 & 0.06 & 1.7 & 1.96 & 0.9 & 0.82 & 0.97 & 1.2 \\
\hline 16 & 0.89 & 1.19 & 0.33 & 0.32 & 0.48 & 0.46 & 1.01 & 1.21 & 0.32 & 0.31 & 0.46 & 0.41 & 0.8 & 0.76 & 0.22 & 0.22 & 0.22 & 0.09 & 0.59 & 0.55 & 0.16 & 0.16 & 0.16 & 0.06 & 1.73 & 1.95 & 0.91 & 0.83 & 0.97 & 1.2 \\
\hline 17 & 0.79 & 1.18 & 0.33 & 0.32 & 0.49 & 0.46 & 0.93 & 1.2 & 0.32 & 031 & 0.46 & 0.41 & 0.78 & 0.74 & 0.22 & 0.21 & 0.22 & 0.09 & 0.58 & 0.53 & 0.16 & 0.1 & 0.16 & 0.06 & 1.65 & 1.97 & 0.93 & 0.84 & 0.99 & 1.2 \\
\hline 18 & 0.54 & 1.03 & 0.3 & 0.29 & 0.45 & 0.46 & 0.6 & 1 & 0.28 & 0.27 & 0.42 & 0.41 & 0.47 & 0.47 & 0.16 & 0.15 & 0.16 & 0.09 & 0.34 & 0.34 & 0.12 & 0.11 & 0.12 & 0.06 & 1.52 & 1.96 & 0.88 & 0.8 & 0.96 & 1.2 \\
\hline 19 & 0.67 & 1.18 & 0.34 & 0.33 & 0.5 & 0.46 & 0.77 & 1.16 & 0.32 & 0.31 & 0.47 & 0.41 & 0.62 & 0.58 & 0.18 & 0.17 & 0.18 & 0.09 & 0.45 & 0.41 & 0.13 & 0.13 & 0.13 & 0.06 & 1.68 & 2.11 & 0.98 & 0.89 & 1.06 & 1.2 \\
\hline 20 & 0.7 & 0.93 & 0.27 & 0.26 & 0.37 & 0.42 & 0.74 & 0.92 & 0.26 & 0.25 & 0.35 & 0.38 & 0.44 & 0.45 & 0.17 & 0.17 & 0.17 & 0.09 & 0.3 & 0.3 & 0.12 & 0.12 & 0.12 & 0.06 & 1.45 & 1.88 & 0.78 & 0.71 & 0.86 & 1.24 \\
\hline 21 & 0.5 & 1.41 & 0.19 & 0.24 & 0.6 & 0.38 & 0.54 & 1.33 & 0.18 & 020 & 0.55 & 0.34 & 0.42 & 0.41 & 0.14 & 0.11 & 0.17 & 0.1 & 0.27 & 0.27 & 0.1 & 0.08 & 0.12 & 0.06 & 2.03 & 3.43 & 0.88 & 0.93 & 1.77 & 1.63 \\
\hline 22 & 0.31 & 0.84 & 0.43 & 0.4 & 0.54 & 0.47 & 0.29 & 0.8 & 0.41 & 0.98 & 0.53 & 0.43 & 0.19 & 0.2 & 0.17 & 0.16 & 0.17 & 0.1 & 0.12 & 0.13 & 0.11 & 0.11 & 0.11 & 0.06 & 1.12 & 1.21 & 0.68 & 0.61 & 0.68 & 1.16 \\
\hline 23 & 0.91 & 1.23 & 0.36 & 0.34 & 0.51 & 0.41 & 1.01 & 1.23 & 0.34 & 0.33 & 0.48 & 0.37 & 0.71 & 0.63 & 0.18 & 0.18 & 0.18 & 0.09 & 0.5 & 0.43 & 0.13 & 0.13 & 0.13 & 0.06 & 1.76 & 2.01 & 0.93 & 0.85 & 1 & 1.3 \\
\hline 24 & 0.13 & 0.83 & 0.43 & 0.4 & 0.55 & 0.47 & 0.14 & 0.79 & 0.41 & 0.38 & 0.54 & 0.42 & 0.18 & 0.18 & 0.16 & 0.16 & 0.16 & 0.09 & 0.11 & 0.11 & 0.1 & 0.1 & 0.1 & 0.06 & 1 & 1.24 & 0.7 & 0.63 & 0.7 & 1.19 \\
\hline 25 & 0.91 & 1.98 & 0.2 & 0.35 & 0.87 & 0.3 & 1.08 & 1.95 & 0.2 & 0.34 & 0.82 & 0.29 & 0.89 & 0.99 & 0.15 & 0.21 & 0.34 & 0.21 & 0.62 & 0.68 & 0.11 & 0.14 & 0.23 & 0.15 & 2.84 & 3.39 & 1.27 & 1.17 & 1.88 & 1.69 \\
\hline 26 & 0.88 & 1.97 & 0.2 & 0.35 & 0.87 & 0.29 & 1.04 & 1.94 & 0.2 & 0.34 & 0.82 & 0.27 & 0.85 & 0.97 & 0.15 & 0.21 & 0.34 & 0.2 & 0.6 & 0.66 & 0.11 & 0.14 & 0.23 & 0.15 & 2.83 & 3.39 & 1.27 & 1.17 & 1.88 & 1.69 \\
\hline
\end{tabular}

scaling parameters $(\alpha=10, \beta=10)$. For summer daytime dry canopy conditions, $V_{d}$ of $\mathrm{HNO}_{3}$ is higher than $1.5 \mathrm{~cm} \mathrm{~s}^{-1}$ for canopies with small roughness lengths and higher than $3 \mathrm{~cm} \mathrm{~s}^{-1}$ for forest canopies with larger roughness lengths. Under wet conditions, $V_{d}$ values are even larger. This is because $R_{a}$ is small (e.g. $<20 \mathrm{~s} \mathrm{~m}^{-1}$ ) under unstable stratification conditions and is in the same magnitude as $R_{c}$. Thus, decreases in $R_{c}$ under rain conditions will increase $V_{d}$. During the nighttime, $\mathrm{HNO}_{3} V_{d}$ is still close to $1.0 \mathrm{~cm} \mathrm{~s}^{-1}$ for canopies with small $z_{0}$ values and even higher for canopies with large $z_{0} \cdot \mathrm{HNO}_{3} V_{d}$ under dry nighttime conditions is slightly larger than under rainy nightgtime conditions, but $V_{d}$ under dew conditions is close (slightly smaller or larger) to that under dry conditions, mainly due to the dominant role of aerodynamic resistance under stable conditions. As discussed earlier, and also shown in Table $4, V_{d}$ of HCHO follows the pattern of $\mathrm{SO}_{2}$ and $V_{d}$ of PAN mimics the pattern of $\mathrm{O}_{3}$. Overall, the typical $V_{d}$ values shown in Table 4 are consistent with the published measurements reviewed by Sehmel (1984), Brook et al. (1999b), Wesely and Hicks (2000) and Zhang et al. (2002a). Again, for many species that do not have measurements, the tables presented here are believed to provide some useful information for applications where deposition velocities are needed.

\section{Conclusions and recommendations}

A revised parameterization for estimating dry deposition velocities in air-quality models that includes a newly developed non-stomatal resistance formulation, a realistic treatment of cuticle and ground resistance in winter (low temperature and snow-covered surfaces) and the handling of seasonally-dependent input parameters (i.e. $L A I, z_{0}$, resistance components) has been found to predict more realistic deposition velocities compared to other existing models, especially for wet canopies. Modelled maximum deposition velocities derived from values of typical meteorological conditions are also found to be realistic compared to published measurements. However, there are few measurements of $V_{d}$ for chemical compounds other than $\mathrm{SO}_{2}, \mathrm{O}_{3}, \mathrm{NO}_{2}, \mathrm{HNO}_{3}$, $\mathrm{NH}_{3}$. Hence, although the approach presented here is expected to be reasonably realistic for those other compounds, 
Table 5. Appendix A: Nomenclature.

\begin{tabular}{|c|c|}
\hline$\alpha:$ & parameter for cuticle and soil resistances scaling to $\mathrm{SO}_{2}(0.0-10.0)$ \\
\hline$\beta:$ & parameter for cuticle and soil resistances scaling to $\mathrm{O}_{3}(0.0-10.0)$ \\
\hline$\psi, \psi_{c 1}, \psi_{c 2}:$ & leaf-water-potential (Mpa) \\
\hline$b_{r s}:$ & empirical light response constant for stomatal resistance $\left(\mathrm{W} \mathrm{m}^{-2}\right)$ \\
\hline$b_{v p d}:$ & water-vapour-pressure-deficit constant $\left(\mathrm{kPa}^{-1}\right)$, \\
\hline$D:$ & vapour pressure deficit $(\mathrm{kPa})$ \\
\hline$e, e^{*}:$ & ambient and saturation water vapour pressure $(\mathrm{kPa})$, respectively. \\
\hline$f_{\text {snow: }}$ & snow cover fraction $(0.0-1.0)$ \\
\hline$L A I:$ & leaf area index $\left(\mathrm{m}^{2} \mathrm{~m}^{-2}\right)$ \\
\hline$r_{\text {smin }}:$ & minimum stomatal resistance $\left(\mathrm{s} \mathrm{m}^{-1}\right)$ \\
\hline$R_{a}:$ & aerodynamic resistance $\left(\mathrm{s} \mathrm{m}^{-1}\right)$. Same unit for all resistance parameters listed below. \\
\hline$R_{a c}, R_{a c 0}:$ & in-canopy aerodynamic resistance \\
\hline$R_{b}:$ & quasi-laminar sublayer resistance \\
\hline$R_{c}:$ & canopy resistance \\
\hline$R_{\text {cut }}:$ & cuticle resistanc \\
\hline$R_{\text {cutd }}, R_{\text {cutd } 0}:$ & dry cuticle resistance \\
\hline$R_{\text {cutw }}, R_{\text {cutw } 0}:$ & wet cuticle resistance \\
\hline$R_{g}:$ & ground resistance \\
\hline$R_{\text {gdew }}, R_{\text {grain }}:$ & soil resistance with dew and rain, respectively \\
\hline$R_{\text {ice }}$ : & ice resistance \\
\hline$R_{m}:$ & mesophyll resistance \\
\hline$R_{n s}:$ & non-stomatal resistance \\
\hline$R_{\text {Snow }}:$ & snow resistance \\
\hline$R_{\text {soil }}:$ & soil resistance \\
\hline$R_{s t}:$ & stomatal resistance \\
\hline$R_{\text {water }}:$ & water resistance \\
\hline$R H:$ & relative humidity $(0-100 \%)$ \\
\hline$s d, s d_{\max }:$ & snow depth $(\mathrm{cm})$ \\
\hline$S R:$ & solar radiation $\left(\mathrm{W} \mathrm{m}^{-2}\right)$ \\
\hline$T_{\min }, T_{\max }, T_{o p t}$ & minimum, maximum and optimum temperature for stomatal opening $\left({ }^{\circ} \mathrm{C}\right)$, respectively. \\
\hline$u_{*}:$ & friction velocity $\left(\mathrm{m} \mathrm{s}^{-1}\right)$ \\
\hline$V_{d}:$ & dry deposition velocity $\left(\mathrm{m} \mathrm{s}^{-1}\right)$ \\
\hline$W_{s t}:$ & fraction of stomatal blocking $(0.0-0.5)$ \\
\hline$z_{0}:$ & roughness length $(\mathrm{m})$ \\
\hline
\end{tabular}

many of the estimated values presented in this paper have not been validated due to the lack of data.

Though the model performs better compared to its earlier version, it clearly still has limitations and uncertainties as discussed in the Introduction. To improve future dry deposition models further evaluations are needed using data from many different sites, especially sites not used for model development. Unfortunately, flux measurements in many locations where dry deposition may be important (e.g. rough terrain, "edges" or step changes in vegetation/land-use) are not possible, though there exist some limited theoretical studies (Physick and Garratt, 1995; De Jong and Klaassen, 1997). Yet air quality models are required to include deposition in such situations. Also, measurements of $\mathrm{SO}_{2}$ deposition over different wetness conditions are needed in order to verify the assumptions made in the present study; and simultaneous flux measurements of $\mathrm{CO}_{2}, \mathrm{H}_{2} \mathrm{O}$ and pollutant gaseous species (e.g. $\mathrm{O}_{3}, \mathrm{SO}_{2}$ ) are needed to verify the assumption that stomatal uptake is not important under wet conditions. It is important to include the compensation point of $\mathrm{NH}_{3}$ for areas where $\mathrm{NH}_{3}$ emission can occur. However, all the information necessary to implement this formulation in regional scale models and/or across multiple locations is not available.

Many chemical species are estimated to have high deposition velocities, yet these have never been measured. Any measurement of flux for these species would be valuable to be able to begin verifying the scaling method. This is probably difficult to measure for species with very low concentrations since no instruments exist with suitable sensitivity and fast enough response time. However, there are approaches for dealing with the fluxes of chemically reactive species, as long as their concentrations are high enough for the measurement techniques. Even soil resistance to different gaseous species over different surfaces (e.g., snow, ice, bare soil, below canopy) needs further investigation. Separate measurements of stomatal and non-stomatal uptake are 
Table 6. Appendix B: Definition of 31 species.

\begin{tabular}{lll}
\hline No. & Symbol & Name \\
\hline 1 & $\mathrm{SO}_{2}$ & Sulphur dioxide \\
2 & $\mathrm{H}_{2} \mathrm{SO}_{4}$ & Sulphuric acid \\
3 & $\mathrm{NO}_{2}$ & Nitrogen dioxide \\
4 & $\mathrm{O}_{3}$ & Ozone \\
5 & $\mathrm{H}_{2} \mathrm{O}_{2}$ & Hydrogen peroxide \\
6 & $\mathrm{HNO}_{3}$ & Nitric acid \\
7 & $\mathrm{HONO}$ & Nitrous acid \\
8 & $\mathrm{HNO} 4$ & Pernitric acid \\
9 & $\mathrm{NH}_{3}$ & Ammonia \\
10 & PAN & Peroxyacetylnitrate \\
11 & PPN & Peroxypropylnitrate \\
12 & APAN & Aromatic acylnitrate \\
13 & MPAN & Peroxymethacrylic nitric anhydride \\
14 & $\mathrm{HCHO}$ & Formaldehyde \\
15 & MCHO & Acetaldehyde \\
16 & PALD & C3 Carbonyls \\
17 & $\mathrm{C} 4 \mathrm{~A}$ & C4-C5 Carbonyls \\
18 & $\mathrm{C} 7 \mathrm{~A}$ & C6-C8 Carbonyls \\
19 & ACHO & Aromatic carbonyls \\
20 & MVK & Methyl-vinyl-ketone \\
21 & MACR & Methacrolein \\
22 & MGLY & Methylgloxal \\
23 & MOH & Methyl alcohol \\
24 & ETOH & Ethyl alcohol \\
25 & POH & C3 alcohol \\
26 & CRES & Cresol \\
27 & FORM & Formic acid \\
28 & ACAC & Acetic acid \\
29 & ROOH & Organic peroxides \\
30 & ONIT & Organic nitrates \\
31 & INIT & Isoprene nitrate \\
\hline & &
\end{tabular}

also important for evaluating the stomatal uptake sub-model for the purpose of estimating $\mathrm{O}_{3}$ damage to crops (Ashmore and Fuhrer, 2000; Emberson et al. 2000) and to develop a broader understanding of the relative importance of these two pathways. Clearly, further model developments, beyond what is presented in this paper, relies heavily on the availability of more extensive and detailed measurements in the future.

Acknowledgements. We greatly appreciate S. Belair and J. StJames of the Canadian Meteorological Center in Montreal for providing GEM related information, M. D. Moran, P. A. Makar, R. Staebler and several AURAMS group members of the Meteorological Service of Canada for helpful comments and P. L. Finkelstein of USEPA for sharing measurement data. Constructive comments from three anonymous reviewers are also appreciated.

\section{References}

Ashmore, M. and Fuhrer, J.: New Directions: Use and abuse of the AOT40 concept, Atmos. Environ., 34, 1157-1158, 2000.
Baldocchi, D. D.: A multi-layer model for estimating sulfur dioxide deposition to a deciduous oak forest canopy, Atmos. Environ., 22, 869-884, 1988.

Baldocchi, D. D., Hicks, B. B., and Camara, P.: A canopy stomatal resistance model for gaseous deposition to vegetated surfaces, Atmos. Environ., 21, 91-101, 1987.

Brook, J., Zhang, L., Franco, D., and Padro, J.: Description and evaluation of a model of deposition velocities for routine estimates of air pollutant dry deposition over North America, Part I: Model development, Atmos. Environ., 33, 5037-5052, 1999a.

Brook, J., Zhang, L., Franco, D., and Padro, J.: Description and evaluation of a model of deposition velocities for routine estimates of air pollutant dry deposition over North America, Part II: Review of past measurements and model results, Atmos. Enviro., 33, 5053-5070, 1999b.

Byun, D. W. and Ching, J. K. S.: Science Algorithms of the EPA Models-3 Community Multiscale Air Quality (CMAQ) Modeling System, EPA/600/R-99/030, Environmental Protection Agency, Office of Research and Development, Washington, DC, 1999.

Carmichael, G. R., Peters, L. K., and Saylor, R. D.: The STEM-II regional scale acid deposition and photochemical oxidant model, 1: An overview of model development and applications, Atmos. Environ., 25, 2077-2090, 1991.

Chameides, W. L.: Acid dew and the role of chemistry in the dry deposition of reactive gases to wetted surfaces, J. Geophys. Res., 92, 11 895-11900, 1987.

Chang, J. S., Brost, R. A., Isaksen, I. S. A., Madronich, S., Middleton, P., Stockwell, W. R., and Walcek, C. J.: A three-dimensional Eulerian acid deposition model: Physical concepts and formulation, J. Geophys. Res., 92, 14 681-14700, 1987.

Coté, J., Desmarais, J. G., Gravel, S., Methot, A., Patoine, A., Roch, M., and Staniforth, A.: The operational CMC/MRB global environmental multiscale (GEM) model, Part I, design considerations and formulation, Mon. Wea. Rev., 126, 1373-1395, 1997.

De Jong, J. J. M. and Klaassen, W.: Simulated dry deposition of nitric acid near forest edges, Atmos. Environ., 31, 3681-3691. 1997.

Dickinson, R. E., Henderson-Sellers, A., Kennedy, P. J., and Wilson, M. F.: Biosphere-Atmosphere Transfer Scheme (BATS) for the NCAR Community Climate Model. NCAR Technical Note NCAR/TN275+STR, National Centre for Atmospheric Research, Boulder, Colorado, 67, 1986.

Dorman, J. L. and Sellers, P. J.: A global climatology of albedo, roughness length and stomatal resistance for atmospheric general circulation models as represented by the simple biosphere model (SiB), J. Appl. Meteor., 28, 833-855, 1989.

Duyzer, J. and Fowler, D.: Modelling land atmosphere exchange of gaseous oxides of nitrogen in Europe, Tellus, Chemical and Physical Meteorology, 46B, 353-372, 1994.

Emberson, L. D., Ashmore, M. R., Cambridge, H. M., Simpson, D., and Tuovinen, J. P: Modelling stomatal ozone flux across Europe, Environ. Pollu., 109, 403-413, 2000.

Erisman, J. W. and Wyers, G. P.: Continuous measurements of surface exchange of $\mathrm{SO}_{2}$ and $\mathrm{NH}_{3}$ : implications for their possible interaction in the deposition process, Atmos. Environ., 27, 19371949, 1993.

Erisman, J. W., van Elzakker, B. G., Mennen, M. G., Hogenkamp, J., Zwart, E., van den Beld, L., Römer, F. G., Bobbink, R., Heil, 
G., Raessen, M., Duyzer, J. H., Verhage, H., Wyers, G. P., Otjes, R. P., and Mols, J. J.: The Elspeetsche Veld experiment on surface exchange of trace gases: Summary of results, Atmos. Enviro., 28, 487-496, 1994a.

Erisman, J. W., Van Pul, A., and Wyers, G. P.: Parameterization of surface resistance for the quantification of atmospheric deposition of acidifying pollutants and ozone, Atmos. Environ., 28, 2595-2607, 1994b.

Finkelstein, P. L., Ellestad, T. G., Clarke, J. F., Meyers, T. P., Schwede, D., Hebert, E. O., and Neal, J. F.: Ozone and sulfur dioxide dry deposition to forests: observations and model evaluation, J. Geophy. Res., 105, 15 365-15 377, 2000.

Flechard, C. R., Fowler, D., Sutton, M. A., and Cape, J. N.: A dynamic chemical model of bi-directional ammonia exchange between semi-natural vegetation and the atmosphere, Q. J. R. Meteoro. Soc., 125, 2611-2641, 1999.

Fowler, D. and Unsworth, M. H.: Turbulent transfer of sulphur dioxide to a wheat crop. Quarterly J. Royal Metro. Soc., 105, 767-783, 1979.

Fuentes, J. D., Gillespie, T. J., den Hartog, G., and Neumann, H. H.: Ozone deposition onto a deciduous forest during dry and wet conditions, Agricultural forest meteorology 62, 1-18, 1992.

Ganzeveld, L. and Lelieveld, J.: Dry deposition parameterization in a chemistry general circulation model and its influence on the distribution of reactive trace gases, J. Geophys. Res., 100, 20 999-21 012, 1995.

Gao, W., Wesely, M. L., and Doskey, P. V.: Numerical modeling of the turbulent diffusion and chemistry of $\mathrm{NO}_{\mathrm{x}}, \mathrm{O}_{3}$, isoprene, and other reactive trace gases in and above a forest canopy, J. Geophys. Res., 98, 18339-18353, 1993.

Grantz, D. A., Zhang, X. J., Massman, W. J., Den Hartog, G., Neumann, H. H., and Pederson, J. R.: Effects of stomatal conductance and surface wetness on ozone deposition in field-grown grape, Atmos. Enviro., 29, 3189-3198, 1995.

Gunthardt-Goerg, M. S., Mcquattie, C. J., Scheidegger, C., Rhiner, C., and Matyssek, R.: Ozone-induced cytochemical and ultrastructrual changes in leaf mesophyll cell walls, Canadian J. Forest Res., 27, 453-463, 1997.

Harley, R. A., Russell, A. G., McRae, G. J., Cass, G. R., and Seinfeld, J. H.: Photochemical modeling of the Southern California Air Quality Study, Environ. Sci. Tech., 27, 378-388, 1993.

Hicks, B. B., Baldocchi, D. D, Meyers, T. P., Hosker Jr., R. P., and Matt, D. R.: A preliminary multiple resistance routine for deriving dry deposition velocities from measured quantities, Water, Air and Soil Pollu., 36, 311-330, 1987.

Hicks, B. B. and Liss, P. S.: Transfer of $\mathrm{SO}_{2}$ and other reactive gases across the air-sea interface, Tellus 28, 348-354, 1976.

Husted, S., Schjoerring, J. K., Nielsen, K. H., Nemitz, E., and Sutton, M. A.: Stomatal compension points for ammonia in oilseed rape plants under field conditions, Agri. For. Metero., 105, 371$383,2000$.

Janssen, L. H. J. M. and Romer, F. G.: The frequency and duration of dew occurrence over a year, Tellus, 43B, 408-419, 1991.

Jarvis, P. G.: The interpretation of the variations in leaf water potential and stomatal conductance found in canopies in the field, Phil. Trans. R. Soc. London Ser. B, 273, 593-610, 1976.

Kramm, G., Dlugi, R., Dollard, G. J., Foken, T., Moelders, N., Mueller, H., Seiler, W., and Sievering H.: On the dry deposition of ozone and reactive nitrogen species, Atmos. Environ. 29,
3209-3231, 1995.

Lamaud, E., Carrara, A., Brunet, Y., Lopez, A., and Druilhet, A.: Ozone fluxes above and within a pine forest canopy in dry and wet conditions, Atmos. Environ., 36, 77-88, 2002.

Laville, P., Cellier, P., Lamaud, E., and Lopez, A.: Micrometeorological measurements of ozone fluxes on a maize crop during the ESCOMPTE experiment, Presented at Joint International Symposium on Atmospheric Chemistry within the Earth System, 1825 September 2002, Crete, Greece, Abstract and Poster, 2002

Lopez, A., Bouchou, P., Brustet, J. M., and Fontian, J.: Ozone vertical fluxes at the interface vegetation-atmosphere, Presented at Joint International Symposium on Atmospheric Chemistry within the Earth System, 18-25 September 2002, Crete, Greece, Abstract and Poster, 2002.

Massman, W. J., Musselman, R. C., and Lefohn, A. S.: A conceptual ozone dose-response model to develop a standard to protect vegetation, Atmos. Environ., 34, 745-759. 2000.

Massman, W. J., Pederson, J., Delany, A., Grantz, D., den Hartog, G., Neumann, H. H., Oncley, S. P., Pearson, R., and Shaw, R. H.: An evaluation of the Regional Acid Deposition Model surface module for ozone uptake at three sites in the San Joaquin Valley of California, J. Geophys. Res., 99, 8281-8294, 1994.

Meyers, T. P., Finkelstein, P. L., Clarke, J., Ellestad, T. G., and Sims, P. F.: A multi-layer model for inferring dry deposition using standard meteorological measurements, J. Geophy. Res., 103, 22 645-22 661, 1998.

McDonald-Buller, E. C., Liljestrand, H. M., and Sepehrnoori, K.: Numerical modeling of dry deposition coupled to 22 photochemical reactions, Atmos. Environ., 33, 1491-1502, 1999.

Moran, M. D., Dastoor, A., Gong, S. L., Gong, W., and Makar, P. A.: Proposed conceptual design for the AES regional particulatematter model/unified model, Unpublished report, Meteorological Service of Canada, Downsview, Ontario, Canada, 1998.

Musselman, R. C. and Minnick, T. J.: Nocturnal stomatal conductance and ambient air quality standards for ozone, Atmos. Environ., 34, 719-733, 2000.

NOAA: NOAA library of input data for "Bigleaf" and "Multi-layer' models, ATDD, NOAA, Oak Ridge, TN, 1992.

Padro, J.: Summary of ozone dry deposition velocity measurements and model estimates over vineyard, cotton, grass and deciduous forest in summer, Atmos. Environ., 30, 2363-2369, 1996.

Padro, J., den Hartog, G., and Neumann, H. H.: An investigation of the ADOM dry deposition module using summertime $\mathrm{O}_{3}$ measurements above a deciduous forest, Atmos. Environ., 25, 16891704, 1991.

Panofsky, H. A. and Dutton, J. A.: Atmospheric Turbulence, Models and Methods for Engineering Applications, John Wiley, New York, 1984.

Physick, W. L. and Garratt, J. R.: Incorporation of a high-roughness lower boundary into a mesoscale model for studies of dry deposition over complex terrain, Boundary-Layer Meteoro., 74, 55-71, 1995.

Pielke, R. A.: Mesoscale Meteorological Modelling, Academic Press, New York, 1984.

Pleim, J. E. and Xiu, A.: Development and testing of a surface flux and planetary boundary layer model for application in mesoscale models, J. Appl. Meteor., 34, 16-32, 1995.

Sehmel, G. A: Deposition and resuspension, In Atmospheric science and power production, edited by Randerson, D., NTIS, 
Springfield, VA, 533-583, 1984.

Scire, J. S.: A review of the UAM-V dry deposition algorithm and recommendations for dry deposition modeling in the LMOS study region, Sigma Research Corporation, Westford, MA (Document A195-100), 1991.

Sellers, P. J., Randall, D. A., Collatz, J. G., Berry, J. A., Field, C. B., Dazlich, D. A., Collelo, G. D., and Bounoua, L.: A revised land surface parameterization (SiB2) for atmospheric GCMs, Part I: Model formulation, J. of Climate, 9, 676-705,1 996.

Singles, R., Sutton, M. A., and Weston, K. J.: A multi-layer model to describe the atmospheric transport and deposition of ammonia in Great Britain, Atmos. Environ., 32, 393-399, 1998.

Smith, R. I., Fowler, D., Sutton, M. A., Flechard, C., and Coyle, M.: Regional estimation of pollutant gas dry deposition in the UK: Model description, sensitivity analyses and outputs, Atmos. Environ., 34, 3757-3777, 2000.

Sorteberg, A. and Hov, O.: Two parametrizations of the dry deposition exchange for $\mathrm{SO}_{2}$ and $\mathrm{NH}_{3}$ in a numerical model, Atmos. Enviro., 30, 1823-1840, 1996.

Sutton, M. A., Burkhardt, J. K., Guerin, D., Nemitz, E., and Fowler, D.: Development of resistance models to describe measurements of bi-directional ammonia surface atmospheric exchange, Atmos. Environ., 32, 473-480, 1998.

Tarnay, L. W., Gertler, A., Taylor Jr., G. E.: The use of inferential models for estimating nitric acid vapor deposition to semi-arid coniferous forests, Atmos. Environ., 36, 3277-3287, 2002.

Tetzlaff, G., Dlugi, R., Friedrich, K., Gross, G., Hinneburg, D., Pahl, U., Zelger, M., and Moelders, N.: On modeling dry deposition of long-lived and chemically reactive species over heterogeneous terrain, J. Atmos. Chem., 42, 123-155, 2002.
Wesely, M. L.: Parameterization of surface resistances to gaseous dry deposition in regional-scale numerical models, Atmos. Environ., 23, 1293-1304, 1989.

Wesely, M. L., Sisterson, D. L., and Jastrow, J. D.: Observations of the chemical properties of dew on vegetation that affect the dry deposition of $\mathrm{SO}_{2}$, J. Geophy. Res., 95, 7501-7514, 1990.

Wesely, M. L. and Hicks, B. B.: A review of the current status of knowledge in dry deposition, Atmos. Environ., 34, 2261-2282, 2000.

Wesely, M. L., Doskey, P. V., and Shannon, J. D.: Deposition Parameterizations for the Industrial Source Complex (ISC3) Model, report to U.S. EPA, Argonne National Laboratory, USA, 2001.

Wiser, G. and Havranek, W. M.: Ozone uptake in the sun and shade crown of spruce: quantifying the physiological effects of ozone exposure, Trees, 7, 227-232, 1993.

Wiser, G. and Havranek, W. M.: Environmental control of ozone uptake in Larix decidua Mill: a comparison between different altitudes, Tree Physiology, 15, 253-258, 1995.

Wu, Y., Brashers, B., Finkelstein, P. L., and Pleim, J. E.: A multilayer biochemical dry deposition model, 1 . Model formulation, J. Geophy. Res., 108 D1, 4013, doi:10.1029/2002JD002293, 2003.

Zhang, L., Moran, M., Makar, P., Brook, J., and Gong, S.: Modelling Gaseous Dry Deposition in AURAMS A Unified Regional Air-quality Modelling System, Atmos. Environ., 36, 537-560, 2002 a.

Zhang, L., Brook, J., and Vet, R.: On Ozone dry deposition With emphasis on non-stomatal uptake and wet canopies, Atmos. Environ., 36, 4787-4799, 2002b.

Zhang, L., Brook, J., and Vet, R.: Evaluation of a non-stomatal resistance parameterization for $\mathrm{SO}_{2}$ dry deposition, Atmos. Environ., 37, 2941-2947, 2003. 